Don M. Chance, CFA

Center for the Study of Futures and Options Markets

The R.B. Pamplin College of Business

Virginia Polytechnic Institute and State University

\title{
Managed Futures and Their Role in Investment Portfolios
}

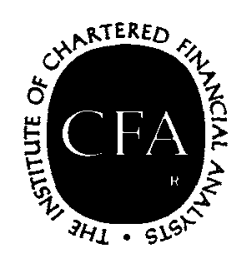

The Research Foundation of

The Institute of Chartered Financial Analysts 


\section{Research Foundation Publications}

Active Currency Management

by Murali Ramaswami

Canadian Stocks, Bonds, Bills, and Inflation: 1950-1987

by James E. Hatch and Robert E. White

Closed-Form Duration Measures and Strategy Applications

by Nelson J. Lacey and Sanjay K. Nawalkha

Corporate Bond Rating Drif: An Examination of Credit Quality Rating Changes Over Time

by Edward I. Altman and Duen Li Kao

Default Risk, Mortality Rates, and the Performance of Corporate Bonds by'Edward I. Altman

Durations of Nondefault-Free Securities by Gerald $\mathrm{O}$. Bierwag and George G. Kaufman

Earmings Forecasts and Share Price Reversals by Werner F.M. De Bondt

The Effect of Illiquidity on Bond Price Data: Some Symptoms and Remedies

by Oded Sarig and Arthur Warga

Equity Trading Costs

by Hans R. Stoll

Ethics, Faimess, Efficiency, and Financial Markets

by Hersh Shefrin and Meir Statman

Ethics in the Investment Profession: A Survey by $\mathrm{E}$. Theodore Veit, CFA, and Michael $\mathrm{R}$. Murphy, CFA

The Founders of Modem Finance: Their Prize-Winning Concepts and 1990 Nobel Lectures

Franchise Value and the Price/Earmings Ratio by Martin L. Leibowitz and Stanley Kogelman
Fundamental Considerations in Cross-Border Investment: The European View

by Bruno Solnik

Global Asset Management and Performance Attribution

by Denis S. Karnosky, Ph.D., and Brian D. Singer, CFA

Initial Public Offerings: The Role of Venture Capitalists

by Joseph T. Lim and Anthony Saunders

The Moderm Role of Bond Covenants by Ileen B. Malitz

A New Method for Valuing Treasury Bond Futures Options by Ehud I. Ronn and Robert R. Bliss, Jr.

A New Perspective on Asset Allocation by Martin L. Leibowitz

Options and Futures: A Tutorial by Roger G. Clarke

The Poison Pill Anti-Takeover Defense: The Price of Strategic Deterrence by Robert F. Bruner

A Practitioner's Guide to Factor Models

Program Trading and Systematic Risk by A.J. Senchack, Jr., and John D. Martin

The Role of Risk Tolerance in the Asset Allocation Process: A New Perspective

by W.V. Harlow III, CFA, and Keith C. Brown, CFA

Selecting Superior Securities by Marc R. Reinganum

Stock Market Structure, Volatility, and Volume

by Hans R. Stoll and Robert E. Whaley

Stocks, Bonds, Bills, and Inflation:

Historical Returns (1926-1987)

by Roger G. Ibbotson and Rex A. Sinquefield (Published with Irwin Professional Publishing) 
Managed Futures and Their Role in Investment Portfolios 
(C) 1994 The Research Foundation of the Institute of Chartered Financial Analysts

All rights reserved. No part of this publication may be reproduced, stored in a retrieval system, or transmitted, in any form or by any means, electronic, mechanical, photocopying, recording, or otherwise, without the prior written permission of the copyright holder.

This publication is designed to provide accurate and authoritative information in regard to the subject matter covered. It is sold with the understanding that the publisher is not engaged in rendering legal, accounting, or other professional service. If legal advice or other expert assistance is required, the services of a competent professional should be sought.

ISBN 978-0-943205-78-6

Printed in the United States of America

April 1994 


\section{Mission}

The mission of the Research Foundation is to identify, fund, and publish research material that:

- expands the body of relevant and useful knowledge available to practitioners;

- assists practitioners in understanding and applying this knowledge; and

- enhances the investment management community's effectiveness in serving clients.

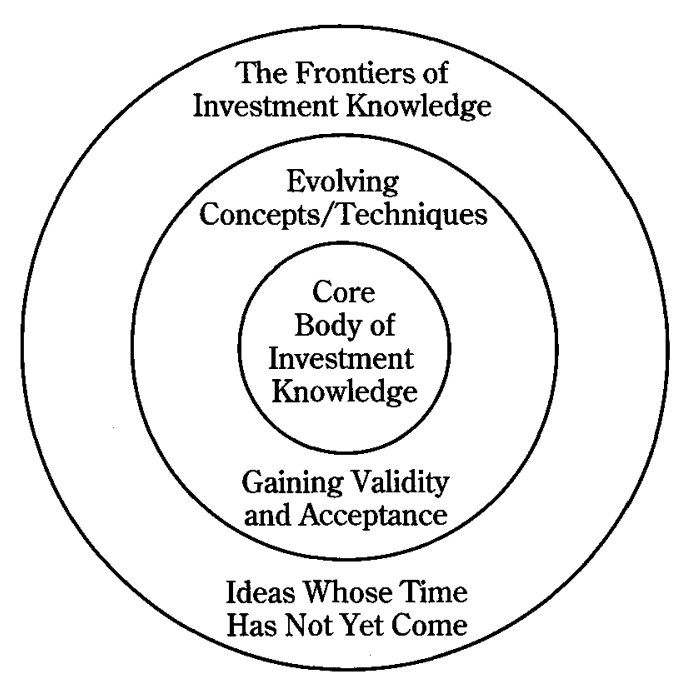

The Research Foundation of

The Institute of Chartered Financial Analysts

P.O. Box 3668

Charlottesville, Virginia 22903

U.S.A.

Telephone: 804/977-6600

Fax: 804/977-1103 


\section{Table of Contents}

Foreword $\ldots \ldots \ldots \ldots \ldots \ldots$ viii

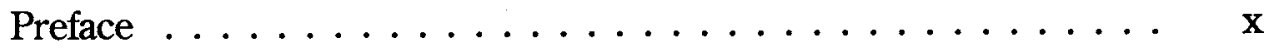

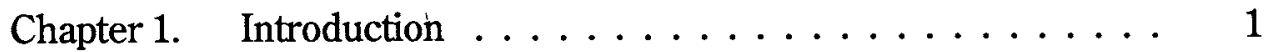

Chapter 2. The Managed Futures Industry . . . . . . . . . 4

Chapter 3. Advantages and Disadvantages of

Managed Futures . . . . . . . . . . . . 9

Chapter 4. The Performance of Managed Futures . . . . . . . 29

Chapter 5. Evaluating the Performance of a

Managed Futures Program . . . . . . . . . . . . . 37

Chapter 6. Legal, Regulatory, Accounting, and

Tax Considerations in Managed Futures . . . . . . . . 49

Chapter 7. Setting Up a Managed Futures Program . . . . . . . . 53

Chapter $8 . \quad$ Summary . . . . . . . . . . . . . . . . . . 59

Appendix A. Measures of Passive and Managed

Futures Performance . . . . . . . . . . . 61

Appendix B. Sources of Information on Managed Futures . . . . . . 69

References and Bibliography on Managed Futures . . . . . . . 72

Order Form $\ldots \ldots \ldots \ldots \ldots \ldots \ldots \ldots$

Selected AIMR Publications $\ldots \ldots \ldots \ldots \ldots$ 


\section{Foreword}

Although futures contracts have existed for as long as markets have existed, only recently have futures gained acceptance as legitimate and viable investments-and only by some professional investment managers. In this monograph, Don Chance convincingly argues that futures offer an attractive outlet for investments and should no longer be regarded as a kind of second-class asset group in comparison with stocks and bonds. Rather, when combined with other asset groups, futures offer a means to enhance a portfolio's risk and return attributes. Professor Chance further contends that futures managers should be regarded in a manner similar to their counterparts in stock and bond investment management.

Many managers remain skeptical, however, about the value and appropriateness of including futures in institutional portfolios. They claim that these securities are too speculative and complex. Furthermore, the skeptics believe, the futures markets are not sufficiently organized to accommodate sizable institutional trading activity.

Nevertheless, the increased acceptability of futures and futures managers has led to the development of a managed futures industry. The growing importance of this industry roughly coincides with the evolution of Modern Portfolio Theory. According to MPT, the overall market consists of all varieties of assets-not merely the traditional stocks, bonds, and money market equivalents. When properly combined, the various asset classes produce a portfolio with a risk-return profile that is superior to a portfolio confined to fewer asset groups. Thus, managed futures, as a distinct asset class, add diversification benefits to a portfolio.

Because of the benefits futures offer a portfolio, the infant managed futures industry is likely to be embraced by more and more investment managers. Literature about this vital topic is sparse, however. Thus, Chance's monograph is extremely important to practicing investment managers. Chance contributes a comprehensive overview of managed futures as an investment vehicle and, as a result, provides a valuable guide to the manager who is contemplating the inclusion of futures in a portfolio.

Of paramount importance to the understanding of any new topic is the author's ability to transmit a comprehensive and understandable treatise on the subject. In that respect, Professor Chance's coherent and convincing communication offers a valuable education to any open-minded investment professional. After beginning with a discussion of the evolution of the managed futures industry, the author proceeds to delve into the many reasons for 
including managed futures in a portfolio. Of major importance is that futures provide the only vehicle through which certain assets can be reasonably accessed. Moreover, in an MPT context, many of these assets have low correlations with other, more traditional assets. Futures may also serve as an effective inflation hedge, and they offer unique short-selling and leverage possibilities.

In his advocacy of this asset class, Chance maintains an unbiased perspective in his presentation by also addressing the drawbacks of managed futures. Trading costs are high, and the overall market capacity remains subject to doubt. The prices of the assets can fluctuate wildly. Even the performance of the professional managers is subject to fairly high volatility. Furthermore, this market's negative image causes executives and trustees to shy away from the use of managed futures. Chance concludes, however, that the benefits of managed futures outweigh the disadvantages.

Although Professor Chance provides an outstanding discussion of the evolution and uses of the managed futures market, his most valuable contribution may be his tutorial about how actually to establish a managed futures program. He provides an eloquent explanation of the steps to follow in setting up such a program, shows how to evaluate the performance of managed futures, and delves into the key legal, regulatory, accounting, and tax considerations attending these assets.

Managed futures seem destined to gain further acceptance by professional investment managers. In this monograph, Don Chance presents a complete tutorial on the subject. From it, interested managers can gain an appreciation of these assets and learn how best to incorporate them in existing portfolios. The Research Foundation of the Institute of Chartered Financial Analysts is pleased to have sponsored this timely and needed tutorial.

John W. Peavy III, CFA

Research Director

The Research Foundation of

The Institute of Chartered Financial Analysts 


\section{Preface}

The spring of 1991 was when I first heard that the Virginia Retirement System (VRS) had made a decision to commit about $\$ 100$ million of its $\$ 12$ billion portfolio to managed futures. My first reaction was relief that I had several years earlier chosen to move my retirement funds to TIAA-CREF. In spite of the fact that I had been a teacher and researcher in the derivatives area since about 1982, I had little confidence that a program of futures trading would add to a portfolio's performance.

I had read the articles demonstrating low correlations between managed futures returns and stock and bond returns, but much of the early research had used data on returns from futures funds, which had a well-deserved reputation for being extremely costly. Expense ratios of 20 percent were then, and are today, quite common.

My initial reaction to the VRS's decision notwithstanding, I decided to take a closer look at this industry than I had in the past. Although I found that exorbitant costs still await those who choose to pay them, I also found that arrangements that provide a reasonable risk-return trade-off after costs are possible. The industry is young and growing, and many firms are willing to compete not only on the basis of gross returns but also on the basis of costs. I was pleasantly surprised. Thus, I began extensive research on the industry, and this monograph is the culmination of that research.

Ever since I took the Level I CFA exam in 1984, I have had a close association with the Institute of Chartered Financial Analysts and, now, its parent, AIMR. Through grading exams and teaching review courses to CFA candidates, I have learned that most of the securities industry is dominated by traditional equity and fixed-income managers who do not trade derivatives, in spite of the tremendous growth in the use of derivatives since the mid-1980s. I have also learned, however, that the typical AIMR member has a thirst for knowledge about new ways to improve a portfolio's risk-return potential. The early reluctance to accept options and futures, therefore, is slowly being overcome. My hope is that this monograph will further dispel that reluctance and show that derivatives have a part in many portfolios.

Managed futures are not for everyone, a point that I hope I have made clear throughout this monograph. Managed futures are certainly worth a look, however, by nearly every portfolio manager, and I certainly hope I have made that point equally clear.

Many individuals assisted in the research process for this final product. I would like to thank particularly the Research Foundation of the ICFA and 
AIMR for their support. In addition, the following individuals provided valuable input, data, or advice during the project: John Rowsell and Matt Moran (Chicago Mercantile Exchange), Pat Catania (Chicago Board of Trade), Clark Heston (Illinois Institute of Technology), Robert Kelly (MC Baldwin), Joe Nichols (Hart Bornhoft), Andy Good (Managed Futures Association), Matt Smith (Amoco), Sol Waksman (Barclay Trading Group), Tim Rudderow (Mount Lucas Management), Daniel Stark (Stark Research), Terry Young (California Managed Accounts), Bill Seale (George Washington University), and Lois Peltz (Managed Accounts Reports). I would also like to thank Robert Kamphuis, director of development of Virginia Tech's Center for the Study of Futures and Options Markets (CSFOM) and Robert Mackay, director of CSFOM, who read the manuscript and provided extensive comments and suggestions. Thanks also go to Scott Irwin of Ohio State and Illinois, who provided written comments on part of the manuscript. As usual, all errors are mine.

Finally, I thank my wife Jan, my daughter Kim, my research assistant Calin Valsan, and my secretary Dianne Fisher, each of whom provided clerical and/or research assistance.

Don M. Chance, CFA

Blacksburg, Virginia

April 1994 


\section{Introduction}

The world financial markets have undergone a tremendous evolution since the early 1980s. One of the reasons for their growth and development has been the increasing popularity of futures trading. Although futures markets long suffered from distrust, they have now become acceptable investment outlets. Today, the futures markets are an efficient and important complement to the traditional stock and bond markets. Although futures will always suffer something of an (undeserved) image problem, they have now risen to take their proper place in the investment spectrum.

With the futures markets appropriately regarded as legitimate, a specialized profession of futures investment managers has naturally developed. Although futures managers have actually been around for as long as the markets have existed, only in recent years have these managers come to be regarded in a manner similar to their counterparts in stock and bond investment management, namely, as honest and serious professional wealth managers. The industry in which professional futures investment managers participate has come to be known as the managed futures industry.

Many large institutional investors recognize that futures are a legitimate investment vehicle, and futures contracts exist on a broad range of assetsstock indexes, foreign currencies, fixed-income securities, metals, grains, and other agricultural products. ${ }^{1}$ Many of the assets included in these groups are not readily available for purchase in spot markets. For example, suppose an equity portfolio manager decided, for some reason, that purchasing soybeans would increase return without a commensurate increase in risk. In order to pursue the investment, he or she would have to take physical possession of the soybeans, incur storage costs, and eventually find a buyer for the beans. Although the strategy might theoretically increase the risk-reward ratio, it would be costly and impractical, which would ultimately undermine the contribution of soybeans to the portfolio. Unless prohibited by trustees or policy, however, the equity manager could take a position in soybeans by trading in

\footnotetext{
${ }^{1}$ Although the focus of this monograph is futures, managed futures traders frequently also use options.
} 
the futures markets. Any price changes in the soybean cash market would be essentially mirrored in the futures market. The costs would be much lower than those of the previous strategy, and the manager would have no need to take possession of the soybeans. The equity manager could capture the risk-reward benefits without the associated problems of holding the physical commodity.

Of course, an equity manager taking a position in soybeans sounds a bit strange, but one should not dismiss this thought too quickly. By holding shares, any stockholder is already taking an indirect position in a variety of products and services provided by firms. Are soybeans really out of place in an investment portfolio? As will be shown later, they and most other commodities are certainly not.

One of the important developments in finance since the late 1960 s has been the evolution of modern portfolio theory. MPT gave analysts a sound theoretical and empirical basis for diversifying portfolios. It presented the case that an individual asset's risk is related to its covariance with all other assets. A central element of MPT is the market portfolio, that elusive measure of aggregate investment wealth. When MPT speaks of the market portfolio, it does not mean merely the S\&P 500 Index or even a much broader index, such as the Wilshire 5000; the market portfolio encompasses all risky assets. That is, the MPT market portfolio includes any asset in which investors might park their wealth-not only stocks, bonds, and commodities but also exotic holdings like antique furniture, comic books, and baseball cards.

Futures, whether transacted directly or by using specialized futures managers, permit access to markets included in the broad definition of the market portfolio but not typically counted in traditional measures of aggregate wealth. This access is only one of the many benefits of futures that will be discussed in this monograph.

In spite of the growing use of derivatives, the traditional financial analyst or portfolio manager normally focuses on cash markets for securities-in many cases, only limited segments of those markets. Although a growing number of financial analysts and portfolio managers is now aware of and using derivatives to some extent, most will not become specialists in futures trading. Most equity and fixed-income managers, indeed, pay little attention to the opportunities afforded by professional futures trading. Herein lies the role of the futures manager.

The purpose of this monograph is to provide a comprehensive overview of managed futures as an investment vehicle. The monograph is directed to the practicing financial analyst/portfolio manager. This reader is assumed to have a basic knowledge of futures, including the institutional characteristics of the 
contracts and markets, and of the simple principles of pricing and hedging. The reader should understand how futures contracts work, what is involved in establishing a futures position, and how the contracts are marked to market each day. Readers who are unfamiliar with these topics are urged to read Clarke (1992), especially Chapters 2 and 3. Other excellent references containing institutional details that are useful in understanding the managed futures industry are Bennett (1992) and Lerner (1989).

The monograph is organized into discussions of the evolution and institutional characteristics of the managed futures industry; the advantages and disadvantages of incorporating managed futures in a portfolio; the various studies of the performance of managed futures; evaluating the performance of a managed futures program; various legal, regulatory, accounting, and tax issues; and setting up a managed futures program. The final chapter summarizes the major conclusion of this study. Appendix A identifies and discusses some measures of trading activity, and Appendix B provides sources of information on managed futures. 


\section{The Managed Futures Industry}

The objective of this chapter is to provide some fundamental background on the origins and current structure of the managed futures industry, which consists of individuals and firms that specialize in managing futures accounts for investors. In addition, the chapter introduces some terms that are commonly used in the industry.

\section{Evolution of Today's Managed Futures Industry}

In the United States, futures have existed since the founding of the Chicago Board of Trade in 1848 . The managed futures industry emerged only 45 years ago, however, with the development of the first commodity fund by Richard Donchian at the firm of Hayden Stone. ${ }^{1}$ A commodity fund is the futures markets' rough equivalent of a mutual fund. Investors deposit money that is consolidated and used for the active trading of futures contracts. ${ }^{2}$

The first professionally managed futures-trading account was established in 1965. The industry did not really take off, however, until the late 1970s. In 1978, the Heinhold Illinois Commodity Fund began offering shares to the general public, and later that year, the first fund was offered by a major brokerage firm. Soon thereafter, the industry reached a size at which its participants decided that a national organization should be formed. The National Association of Futures Trading Advisors (NAFTA) was created in 1980.

Public futures funds were still relatively unknown, however, and suffered from the image problems of the futures markets. Many people did not trust futures markets and believed that futures traders were engaged in dubious speculative activities intended to cheat the public.

In 1983, a major turning point in the evolution of the managed futures industry occurred when Harvard Business School Professor John Lintner

\footnotetext{
${ }^{1}$ This section draws heavily from the excellent review of the origins of the managed futures industry by Jobman (1992b), which in turn, draws from Northcote (1991).

${ }^{2}$ In 1949, futures contracts were referred to almost exclusively as commodity futures; hence, the name commodity funds. Since the early 1970 s, however, futures contracts have also existed on financial instruments and currencies. The term commodity is thus used somewhat less today than in the past, but it can be correctly applied if one recalls that money itself is a commodity.
} 
presented a paper showing that the addition of futures to a portfolio could improve its risk-reward trade-off (Lintner 1983). The industry seized this opportunity to promote its products heavily, and the number of funds grew rapidly, as did the number of privately managed accounts.

In 1986, another organization, the Managed Futures Trading Association (MFTA), was founded. That year was also a landmark in the growing acceptance of professionally managed futures accounts as the Detroit Police and Fireman Pension Fund began futures trading. One year later, Eastman Kodak became the first Fortune 500 firm to use specialized futures traders. ${ }^{3}$ (Its initial commitment of $\$ 50$ million was later expanded to $\$ 200$ million.) The industry entered a period of rapid growth, which included the establishment of a European managed futures industry with a professional organization similar to the MFTA.

In 1991, the NAFTA and the MFTA merged into a single organization, the Managed Futures Association. That year also saw the commitment of $\$ 100$ million to futures trading by the Virginia Retirement System, the first public pension fund to adopt such a program and the largest initial commitment by a retirement plan to futures trading.

In 1992, the dollars committed to managed futures programs leveled off. Nonetheless, the growth has been quite remarkable, as shown by the Managed Accounts Reports (MAR) data in Figure 1. In 1980, the industry was about $\$ 750$ million; by 1991 , it had reached $\$ 21$ billion, a compound growth rate of about 35 percent a year. Figure 1 also shows the size of what MAR describes as the speculative industry. The speculative industry is considered to be the amount of money under the control of futures managers that is invested in pure speculative positions. ${ }^{4}$ That figure grew from $\$ 265$ million in 1980 to $\$ 13.6$ billion in 1991 , a rate of about 43 percent a year.

Not coincidentally, the growth of managed futures has paralleled the growth in the use of financial futures. Although one of the benefits of managed futures is access to commodity markets, most managed futures programs trade heavily in stock, bond, and currency futures markets. The enormous liquidity of those markets has made them much more attractive than the commodities

\footnotetext{
${ }^{3}$ Many large institutional investors have long used futures, however, to manage cash inflows or outflows, to hedge, or to adjust asset allocations. In some cases, the institutions may have employed specialized futures managers. The differences between these institutional programs and the managed futures programs that are the focus of this monograph is subtle. A managed futures program, however, is generally regarded as an ongoing, active program in which futures are viewed as an asset class. A program of managed futures typically involves far more trading than the use of futures as a hedge or asset allocation tool.

'That is, the funds used by programs not for cash management, hedging, or asset allocation.
} 
FICURE 1. Managed Futures Industry Size

(billions of dollars under management)

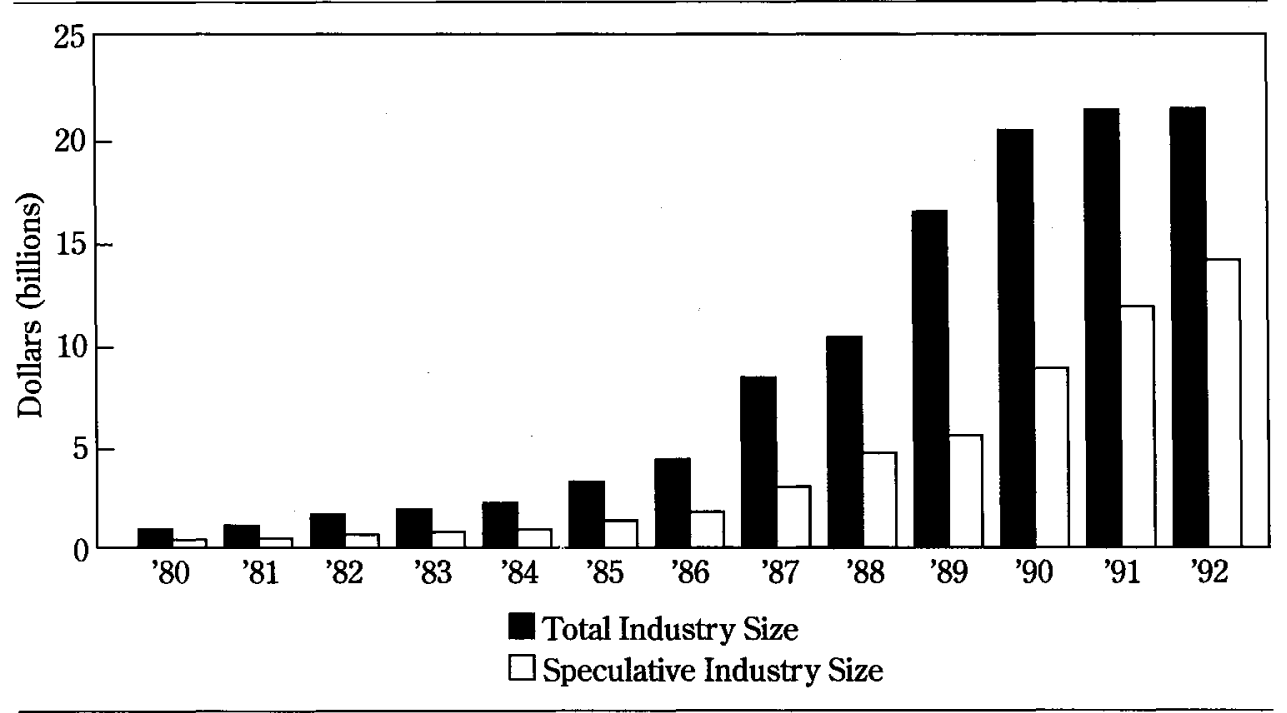

Source: Managed Accounts Reports.

markets to managed futures accounts. Because short selling has several impediments in cash markets, the ability to use futures to take short positions easily in stocks and bonds is particularly valuable. These points will be discussed in detail in Chapter 3.

\section{Types of Futures Accounts ${ }^{5}$}

Public commodity or futures funds are essentially mutual funds offered to the public in much the same manner as stock and bond mutual funds. The funds often require initial deposits of as little as $\$ 2,000$, and in some cases, they guarantee that investors will not lose more than the amount they originally deposited. Futures funds typically take positions, either long or short, in a broad range of futures commodities. Because they are offered to the public, the funds must be registered with the Securities and Exchange Commission and must provide the public with periodic reports. In addition, the Commodity Futures Trading Commission (CFTC) has regulatory authority over futures funds, and state regulations may also apply. The funds are required to prepare detailed prospectuses, the contents of which have generated much debate. Public funds represent about 15 percent of all managed futures accounts.

Private pools, sometimes referred to as commodity pools, are essentially

${ }^{5}$ This section draws heavily from Chicago Board of Trade (1992). 
funds that are offered to a limited number of investors. They require minimum amounts ranging from ten to several hundred thousand dollars and are usually open to fewer than 50 investors. They are typically organized as limited partnerships, meaning that the investor's loss is limited to the original amount invested plus any accumulated profits. These pools are regulated by the CFTC, with which they must be registered. They represent about 55 percent of all managed futures accounts.

Finally, individually managed accounts represent about 30 percent of all managed futures accounts. These individual accounts are private arrangements between an investor and a futures manager in which the manager operates a trading account for the investor. The investor may be an individual or an institution, such as a pension fund. These arrangements are customized to meet the objectives of each investor and may contain specific provisions not commonly found in the other forms of managed futures. In addition, individual accounts have the advantage that the investor can bargain directly with the futures manager to obtain the best terms. In some cases, the investor could have various managers bidding against each other to obtain the account.

All managed futures relationships incur costs, of course, and costs have been one of the most controversial issues in the managed futures business. Costs are discussed in the next chapter.

\section{Traders of Managed Futures}

Individuals who make decisions for or advise others involving the establishment of futures positions are referred to as commodity trading advisors (CTAs). They are essentially professional investment managers whose specialty is futures markets. They are similar in many ways to traditional stock and bond financial analysts and portfolio managers. They have limited powers of attorney. Their analytical styles fall into two familiar groups: fundamental and technical analysis. Fundamentalists focus on analyzing current and expected future conditions concerning weather, crop yields, product demand and supply, interest rates, the economy, and so on. Technicians, like their stock market counterparts, are chartists who believe that the historical patterns of prices reveal something about expected future prices. Although both camps are well represented and some CTAs do both fundamental and technical analysis, technicians are probably more common among CTAs than among stock and bond investment managers. ${ }^{6}$

\footnotetext{
${ }^{6}$ Irwin and Brorsen (1985) estimated that 80 percent of public futures funds use computerbased technical trading systems exclusively and 17 percent of the funds use technical analysis to at least a limited degree together with fundamental analysis. Their study covered the 1975-84 period.
} 
Commodity pool operators (CPOs) organize private commodity pools. The $\mathrm{CPO}$ might market the product directly to private investors or might sell it to brokerage firms, who then sell it directly to the public. A CPO is typically an experienced CTA.

Managers of managers (MOMs) are individuals who oversee a group of CTAs on behalf of a client. The rise of MOMs is a phenomenon of the 1990s. Basically, an MOM is an experienced CTA (and possibly CPO) who selects and evaluates CTAs for the client. MOMs promote their services by emphasizing their ability to find the best performing CTAs, allocate funds to them, monitor their performance, and fire underperformers. MOMs frequently provide considerable back-office support, which includes the daily trading operations, such as meeting margin requirements, generating reports, and monitoring the overall position of the program. In some cases, MOMs also serve as consultants, assisting investors in evaluating whether to establish managed futures programs.

In addition to CTAs, CPOs, and MOMs, many other individuals are involved in futures trading in some fashion. Trades ordered by the CTAs go to a floor broker, for example, who typically works for a futures commission merchant, which is essentially a brokerage firm that executes futures trades. A custodian is also needed; the custodian, usually a bank, has the responsibility of record keeping and overseeing the program in the best interests of the investor.

\section{The Managed Futures Association}

The Managed Futures Association (MFA), founded in 1991, promotes the industry and lobbies the various federal and state agencies and legislatures for favorable regulatory treatment. The MFA's specific goals are stated as follows in its 1992 Membership Directory:

- To promote the activities designed to advance the common purposes of all members of the managed futures industry.

- To actively monitor and interpret legislation and regulations which directly affect the managed futures industry.

- To foster increased public awareness of the managed futures industry.

- To research, develop and distribute educational materials about the managed futures industry.

- To represent values and viewpoints from all segments of the industry and provide resources and support to each of these segments.

- To provide a forum for the exchange of information and the collective resolution of industry problems.

The 1992 Membership Directory lists 396 members worldwide. 


\section{Advantages and Disadvantages of Managed Futures}

Managed futures offer many attractive features that have contributed to their increased popularity. They entail a number of costs, however, both literal and figurative, that must be carefully weighed. This chapter explores both aspects of managed futures programs. Some of the discussion will be relevant to public funds and private pools, but the primary objective is to draw conclusions about the advantages and disadvantages of private arrangements between managed futures professionals and institutional investors.

\section{Advantages}

The advantages managed futures offer a portfolio include access to numerous investment markets, the ease of short selling, low-cost leverage trading, increased liquidity, low correlation with other asset classes, and a possible inflation hedge.

Investment Opportunities. The futures markets, in general, offer access to a broad range of investment markets. For examples, Table 1 lists the different types of commodities on which futures contracts trade. A typical equity or fixed-income portfolio manager would operate in only a limited segment of these markets, of course; securities portfolio managers generally specialize and rarely, if ever, take positions in agricultural products or natural resources.

Suppose, however, that a pension plan decided that it wished to allocate a portion of its funds to agricultural products. How would it achieve this exposure? One way would be to invest in companies whose primary outputs are agricultural products. This approach is difficult, however, because investment in farming is not generally available through corporate ownership. Firms that trade in these products are normally small and sometimes not publicly traded. Shares of large firms that deal in the products are usually available, 


\section{TABLE 1. Commodities on Which U.S. Futures Contracts Are Available}

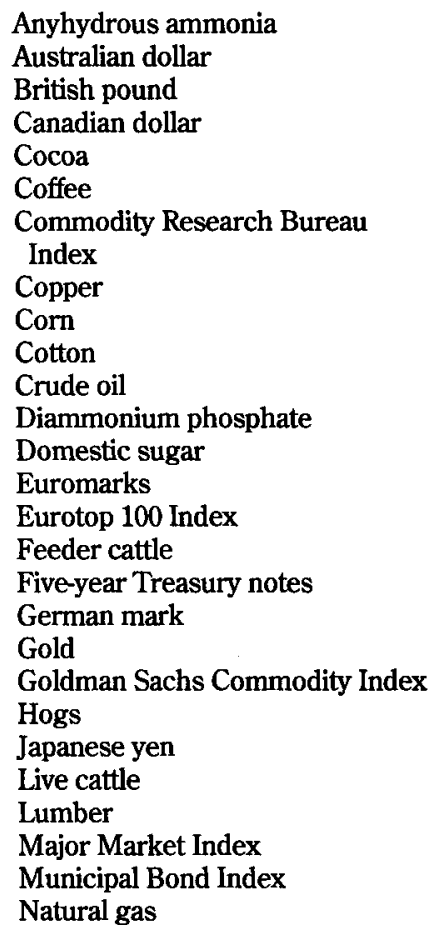

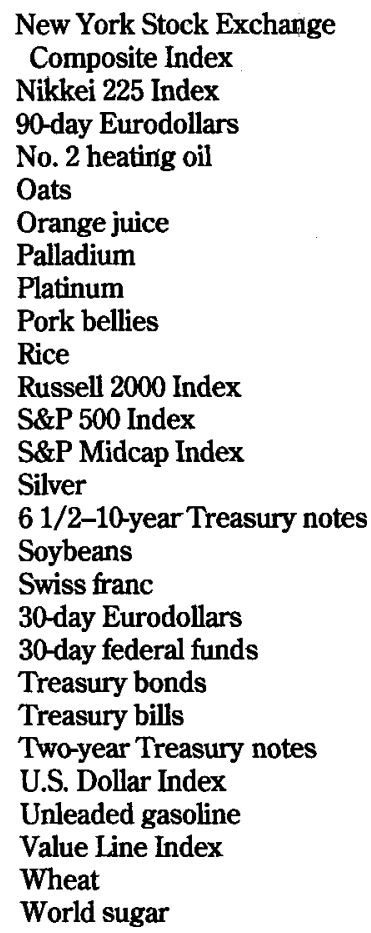

but many of these firms are heavily engaged in nonagricultural activities, the returns from which might not be attractive to the manager. Similar arguments can be made for other classes of commodities. In other words, exposure to these commodity classes is theoretically possible, but such exposure must be taken indirectly through ownership of firms whose performance is tied to the performance of the commodities.

The futures markets offer more direct access to the risk-return opportunities in these markets. This characteristic of the markets raises the immediate question of whether or not futures are a distinct investment opportunity-in other words, a unique asset class. This issue is examined closely in a later section of this chapter, but for the purposes of this section, consider the relationship of futures to the theoretical set of investment opportunities that compose the market portfolio.

The well-known capital asset pricing model (CAPM) of Sharpe (1964), Lintner (1965), and Mossin (1966) can be used to answer this question. The 
CAPM expresses the relationship between the required rate of return on a risky asset and its risk. A fundamental principle underlying the CAPM is that risk-averse investors choose portfolios that provide the maximum return for a given level of risk. Portfolios that maximize return for a given level of risk are called efficient portfolios. The risk of an asset is measured in the CAPM by its beta, which reflects the covariance between the asset's return and the return to the market portfolio of all risky assets.

Although the CAPM is not without its critics, it is a convenient, simple model that has gained widespread acceptance as a basic explanation of the risk-return relationship. ${ }^{1}$ Empirical tests of the CAPM have shown that a simple, linear relationship does apparently exist between expected returns and betas, but these tests have been subject to much criticism. Roll (1977) has demonstrated that if the market portfolio is efficient, an exact linear relationship exists between expected returns and beta. Therefore, Roll's work implies that the only true test of the CAPM is whether the market portfolio is an efficient portfolio. The market portfolio contains all risky investment opportunities. Roll demonstrated that even typical proxies for the market portfolio (e.g., the S\&P 500, the New York Stock Exchange Index) are not satisfactory measures of the risk-return relationship. If the NYSE Index were the true market portfolio and the S\&P 500 were used as a proxy, one could easily demonstrate that the NYSE Index can be efficient (or inefficient) while the S\&P is inefficient (or efficient), even though the two portfolios are extremely highly correlated. Roll concluded that, to test the CAPM legitimately, a proxy is not sufficient; one must measure the market portfolio in its entirety.

Although many have claimed that Roll's argument is too fatalistic, the argument does point out the importance of having a good measure of the market portfolio. Clearly, stocks, bonds, and Treasury bills are not the entire market portfolio; real estate, metals, foreign currencies, and natural resources are surely part of it. In short, many of the kinds of investment opportunities provided by the futures markets are part of the aggregate wealth of society and, hence, are components of the market portfolio. Thus, futures trading brings the "market" closer to the true market portfolio by widening the set of available investment opportunities.

What is the practical significance of this point? Access to the futures markets increases investment opportunities. Investors may choose not to partake of these opportunities, but their availability does no harm and may do some good. Thus, no one is worse off and someone may be better off.

\footnotetext{
${ }^{1}$ For a review of the empirical work on the CAPM, see Chapter 11 of Bodie, Kane, and Marcus (1993).
} 
Ease of Short Selling. One of the basic assumptions of modern portfolio theory is that investors have the ability to sell short. Short selling widens the opportunity set by permitting investors to take positions that offset the risks of long positions and to position themselves to profit from anticipated price declines. This benefit of futures markets can be easily seen by considering the simple case of an equity manager who is pessimistic about the overall market. Assuming that the manager is not restricted from selling short, how would a short sale of the overall market be accomplished?

First, the manager could attempt to construct a short position in a portfolio that replicates the market. Ignoring the aforementioned problems regarding the use of a market proxy, assume that the manager decides to sell short the S\&P 500 Index. This decision dictates that the manager establish a short position in each security in the S\&P 500 according to the proportion that the security comprises of the index. The strategy is theoretically possible, but federal securities laws burden the short seller with heavy margin requirements (all of the proceeds plus 50 percent additional funds) and require that all short sales be performed on an uptick or zero plus tick.

Fortunately, a simple alternative is available. The manager (assuming he or she is not prohibited by policy) can simply sell short the S\&P 500 futures. Short positions in futures are as easy to establish as long positions. The margin requirements are the same as long positions (and considerably less than for short stock positions), and the sale has no uptick requirement. In addition, futures trading has much lower transaction costs than spot trading. ${ }^{2}$ Finally, many (perhaps, most) commodities cannot be sold short at all in the spot market.

Thus, with regard to short selling, futures really have no competition. Remember, however, that the risk of short selling in any market is high. The underlying futures or spot instrument has no upper price limit; thus, in either case, the loss is potentially infinite.

Leverage Trading. Futures markets also permit low-cost leverage trading. A typical futures contract requires that the trader put down 5 percent or less of the price of the contract, and often this requirement can be met by depositing T-bills. A comparable transaction in the stock market would require that the trader put down 50 percent of the purchase price and borrow

\footnotetext{
${ }^{2}$ Low transaction costs are, in fact, one of the primary advantages of futures trading. For a basket of securities comprising the S\&P 500 , the transaction costs of futures trading amount to only a fraction of the cost of trading the securities directly. See Dunford (1990:11-26).
} 
the rest. The loan would incur interest charges at the broker call rate. In the futures market, no loan at all is involved. The deposit is not really a margin transaction but a good-faith deposit. ${ }^{3}$ In addition, the gains, if any, received from profitable leverage trading are guaranteed by the futures clearinghouse. In other words, the opposite party can default, but any losses will be covered by the clearinghouse.

Of course, the risky nature of the leverage transaction should not be deemphasized. The low margin requirement means that the potential gains and losses as a percentage of funds committed are quite high. The leverage factor can be reduced in the futures transaction by depositing the full price of the futures, which is termed collateralizing the futures transaction. There is little reason to do so, however, because the potential loss remains the same.

Liquidity. Futures markets also offer the advantage of a generally high degree of liquidity. Because little capital is required to establish a futures position, most futures contracts have a reasonably large number of traders actively taking positions in them. Of course, each futures commodity has several different contract months. The nearby months are usually the most liquid; the later expirations can be, in fact, quite illiquid. Nevertheless, many futures commodities are fairly liquid over a broad range of contract months. ${ }^{4}$

High liquidity leads to tight bid-ask spreads. Liquidity can be fairly easily gauged by observing volume and open interest, which are reported daily in most financial newspapers. While the exchanges frequently introduce contracts on new commodities that attract little trading interest, these low-liquidity markets are easy to identify and avoid.

The securities markets vary in their degrees of liquidity. The bond market is less liquid than the stock market, and within each of those markets, liquidity is related to the size of the company that issued the security and the size of the bond issue or number of shareholders. The securities markets in general are regarded as quite liquid, but the amount of capital necessary to trade securities relative to the amount necessary to trade futures makes the latter more liquid in general.

\footnotetext{
${ }^{3} \mathrm{~A}$ useful comparison is the purchase of a house. When the buyer makes a bid, the buyer usually puts down a small good-faith deposit. When the transaction is actually completed, the buyer typically takes out a mortgage. The futures margin is similar to the good-faith deposit, a simple indication of an intent to engage in a future transaction. The actual spot-market margin transaction is similar to the mortgage: An asset is purchased, and a portion of the purchase price is borrowed.
}

${ }^{4}$ Eurodollar futures, for example, are quite liquid for expirations up to five years. 
A Distinct Assot Class. Another important, perhaps the most important, benefit of futures trading is that futures may constitute a distinct asset class. Many investment managers, such as asset allocators, follow an investment philosophy that seeks to determine which of the several broad classes of investments will perform best. They then allocate funds-in some cases, using mathematical models-among these classes. The three broadest asset classes might be considered stocks, bonds, and T-bills. Stocks and bonds can be further broken down into small-capitalization stocks, mid-capitalization stocks, foreign stocks, government bonds, corporate bonds, municipal bonds, and high-yield bonds. In addition, exotic asset classes can be identified-gold, real estate, collectibles, and so on.

Exactly what requirements must be met for a set of assets to be recognized as an asset class is not clear, but the factor most often noted is a relatively low correlation between the assets as a group and other asset classes. The research on managed futures has come to the conclusion, based primarily on the low-correlation criterion, that futures are a distinct asset class. In the case of futures, the correlation with other classes is indeed low, particularly with stocks. This low correlation means that the addition of futures to a portfolio can provide diversification.

Modern portfolio theory, as discussed previously, seeks to determine the combination of assets that has the lowest risk for a given level of expected return. The portfolios that achieve the lowest risk for a given level of return are referred to as minimum-variance portfolios. Within the set of minimumvariance portfolios are the aforementioned efficient portfolios, the group of portfolios that achieve the highest expected return for a given level of risk. ${ }^{5}$ Virtually all risk is related to the comovements among the large set of existing securities. Therefore, greater portfolio efficiency cannot be achieved by adding investments whose returns are highly correlated with those already in place. The addition of individual securities typically adds little risk reduction.

Futures trading, however, may enable investors to increase portfolio efficiency for several reasons. First, futures contracts are available on assets that are not included in the typical investment opportunity set. Thus, the returns on these assets may have low correlations with the stocks and bonds that probably compose the current portfolio. Second, futures may contribute to portfolio efficiency by enabling investors to take short positions more easily.

\footnotetext{
${ }^{5}$ Some confusion frequently attends the terms minimum-variance and efficient portfolios. Often, all portfolios that achieve the lowest risk for a given level of return are called efficient portfolios. I make the distinction noted here because it conveniently allows the conclusion that investors choose only efficient portfolios, which are but a subset of the set of minimum-variance portfolios.
} 
For example, certain futures contracts may be highly correlated with certain spot investments. By selling short the futures, the investor can achieve significant risk reduction. ${ }^{6}$ Finally, the returns to managed futures may have a low correlation with stocks and bonds because many commodity trading advisors (CTAs) follow strategies that sometimes pay little attention to the stock and bond markets.

Numerous studies of the performance of passive and active futures trading exist. Many of these studies focus on risk and return, an issue considered in Chapter 5. At this point, the focus is on findings regarding the correlations between futures and the more traditional asset classes.

Bodie and Rosansky (1980) examined the return performance of 23 commodity futures contracts over the period of December 1949 through December 1976. Using quarterly data, they correlated futures returns with common stocks, long-term government bonds, and T-bills. The correlation between futures and stocks was -0.24 ; between futures and bonds, -0.16 ; and between futures and T-bills, 0.34 .

Lintner presented a landmark paper (1983) at an annual conference of the Financial Analysts Federation that briefly mentioned the monthly return performance of 15 CTAs and 8 commodity funds for July 1979 through December 1982. This work was the first study of returns of actual CTAs. Lintner observed that the correlation of the futures fund returns to a stock portfolio was 0.234 and the correlation to a bond portfolio was $0.151{ }^{7}$ The correlation of the CTA returns with the stock portfolio was 0.059 , and the correlation with the bond portfolio was 0.148 . Lintner also combined the stock and bond portfolios into a single portfolio consisting of 60 percent stock and 40 percent bonds. The correlation of the futures fund returns with the combined stock/bond portfolio was -0.024 . The futures managers' returns had a correlation of 0.116 with the stock/bond portfolio. Lintner derived the minimum-variance set and showed that the inclusion of either the returns to the futures funds or the futures managers' returns increased portfolio efficiency. Lintner concluded that futures can lead to significant improvements in the risk-return profile of a portfolio.

Irwin and Brorsen (1985) examined the performance of 84 commodity funds for the period of January 1975 through May 1984. Using quarterly returns,

\footnotetext{
${ }^{6}$ Note, however, that Levy (1987) showed that the optimal portfolio does not necessarily entail short positions in futures.

${ }^{7}$ The stock portfolio was the value-weighted portfolio of NYSE and American Stock Exchange stocks compiled by the Center for Research in Security Prices of the University of Chicago. The bond portfolio was the Salomon Brothers High-Grade, Long-Term Corporate Bond Index.
} 
they estimated the efficient set for a combination of stocks, bonds, T-bills, and futures funds. The correlations between the futures funds and the other asset classes were -0.367 (bills), -0.529 (bonds), and -0.633 (stocks). The authors demonstrated that adding futures to an investment opportunity set consisting of stocks, bonds, and bills can create considerable improvement in portfolio efficiency.

Lee, Leuthold, and Cordier (1985) examined the diversification issue from a different angle. They looked at daily returns to the S\&P 500 Index and the Commodity Research Bureau (CRB) Index for 1978 through 1981. Applying several different tests, they concluded that the two sets of data were statistically independent. $^{8}$

Herbst and McCormack (1986) used monthly data on individual common stocks and futures contracts to determine whether adding futures to randomly selected portfolios could provide diversification. They chose portfolios of 8 , $12,14,16$, and 32 stocks, selected randomly and repeatedly sampled; the time period was not specified. The next step was to add a futures contract and randomly delete a stock. This step was repeated seven times. The results showed that replacing stocks with futures does substantially improve portfolio efficiency. The improvement occurred up to the point at which futures composed about 70 percent of the portfolio.

In an updated study, Herbst and McCormack (1988) used monthly data for the period of January 1980 through November 1984. They constructed two portfolios of 10 and 15 stocks each and randomly added a futures while removing an individual stock. In this study, futures improved portfolio efficiency to the point at which futures composed about 25 percent of the portfolio.

Barat $z$ and Eresian (1986) examined the diversification potential of futures using a set of monthly data on the performance of 12 futures managers for 1980 through 1985. They compared returns to the futures traders with the S\&P 500 Index and a bond portfolio reflecting a weighted average of all Treasury bonds with maturities of ten years or more. They found that the correlation between the overall futures returns and the S\&P 500 was -0.036 and the correlation between the futures returns and the bond portfolio was -0.101 .

Baratz and Eresian also examined the correlations between the individual traders and the S\&P 500 Index and bond portfolios. Eight of the traders had negative correlations with the S\&P 500, and ten had negative correlations with

\footnotetext{
${ }^{8}$ The tests conducted by Lee, Leuthold, and Cordier were described as tests of dependence. The tests were of linear dependence only, however. A nonlinear relationship could exist between stock and futures returns, but much more powerful tests would be needed for its detection.
} 
the bond portfolio. The largest positive trader correlation with the S\&P 500 was 0.322 , and the largest negative correlation was -0.217 . The largest positive trader correlation with the bond portfolio was 0.116 , and the largest negative correlation was -0.196 .

Finally, the authors examined the correlations of the 12 trader returns among themselves. All were highly positively correlated except a single trader, whose correlations were negative in 9 of 11 comparison cases. ${ }^{9}$ The high correlation among trader returns raises questions about whether multiple managers provide any benefits beyond a single manager.

To update their original study, Baratz and Eresian (1990) examined monthly returns for 1984 through 1988 . The correlations of futures with stock and bond returns were slightly but only insignificantly higher than in the earlier study; thus, the previous results were generally upheld during the later time period.

Irwin and Landa (1987) examined the diversification potential of adding real estate, a buy-and-hold futures portfolio, public commodity funds, and gold to a portfolio of stocks and bonds. Using annual returns for the $1975-85$ period, the authors found the buy-and-hold futures portfolio to have correlations of -0.42 with T-bills, -0.33 with bonds, 0.22 with stocks, and 0.49 with real estate. The commodity funds had correlations of -0.54 with bills, -0.47 with bonds, -0.56 with stocks, 0.07 with real estate, and -0.03 with the buy-and-hold futures portfolio. Irwin and Landa also constructed efficient portfolios and found that futures and real estate reduced risk by almost 50 percent and increased return by almost 12 percent.

In a widely cited article in the Journal of Business, Elton, Gruber, and Rentzler (1987) published the first major study that heavily criticized futures funds. They used monthly data on public funds during the period of June 1979 through June 1985; the number of funds varied from 12 to 85 . The authors compared futures funds with stocks (S\&P 500 Index), small-capitalization stocks (the 20 percent lowest capitalization stocks on the NYSE), long-term corporate bonds (the Shearson Lehman Bond Index), long-term government bonds (also Shearson), and T-bills. The futures funds had correlations of -0.121 with stocks, -0.003 with bonds, and 0.010 with T-bills. (Correlations with the other indexes were not reported.) The authors then determined the breakeven average return level required to justify adding futures funds to a portfolio of stocks and bonds. The actual average return on futures funds was

\footnotetext{
${ }^{9}$ The evidence that futures traders' returns are highly correlated among themselves is further supported in a study by Lukac, Brorsen, and Irwin (1988). They argued that the similarity of futures traders' returns arises from the fact that many traders use similar computerized technical trading tools.
} 
not sufficiently high to justify adding them to such a portfolio.

Allen (1992) examined the correlations between several asset classes and the Goldman Sachs Commodity Index (GSCI), the Mount Lucas Management/BARRA Index, and the Managed Accounts Reports Dollar-Weighted Index for the 12-1/4-year period ending March 31, 1992. (Appendix A discusses these indexes.) The three futures indexes had correlations with large-cap equity, small-cap equity, and international equity indexes ranging from -0.13 to -0.30 .

Thus, the agreement appears to be strong that a diversified combination of futures positions has a low, perhaps negative, correlation with the traditional asset classes of stocks and bonds. Although the Elton-Gruber-Rentzler study raises questions about futures funds' diversification potential, the support for at least considering the inclusion of futures in a diversiffed portfolio appears to be solid. Before moving on, however, it may be helpful to examine this issue directly.

Summary statistics for the 1970-92 period for returns on the GSCI, the S\&P 500 Index, the Morgan Stanley Europe, Australia, Far East (EAFE) Index, Treasury bonds, and Treasury bills were generated by Ibbotson Associates (1992) for the Chicago Mercantile Exchange. Table 2 contains the means and standard deviations, and Table 3 contains the correlation coefficients from these data. Figure 2 presents the minimum-variance set for portfolio returns of 2-20 percent, computed with and without the GSCI. The dark line is the minimum-variance set using only the S\&P 500, the EAFE Index, T-bonds, and T-bills. The lighter line is the minimum-variance set recomputed with the GSCI included. Obviously, including the GSCI leads to substantial improvement. Specifically, for any given level of return, the standard deviation of the portfolio when the GSCI is used is approximately one-half the standard deviation of the portfolio without using the GSCI.

Now, however, consider a harder test: the results when more than five different asset classes are used. Table 4 contains mean returns and standard

TABLE 2. Summary Statistics for Five Selected Asset Classes

\begin{tabular}{lcc}
\hline Asset Class & $\begin{array}{c}\text { Mean } \\
\text { (percent) }\end{array}$ & $\begin{array}{c}\text { Standard Deviation } \\
\text { (percent) }\end{array}$ \\
\hline GSCI & 14.78 & 24.66 \\
S\&P 500 Index & 11.46 & 15.60 \\
EAFE Index & 13.08 & 22.84 \\
T-bonds & 9.01 & 7.42 \\
T-bills & 7.46 & 0.41 \\
\hline
\end{tabular}

Source: Ibbotson Associates (1992).

Note: Monthly returns for January 1970 through April 1992. 
TABLE 3. Correlation Matrix for Five Selected Asset Classes

\begin{tabular}{lccccc}
\hline & GSCI & S\&P 500 & EAFE & $\begin{array}{c}\text { Treasury } \\
\text { Bonds }\end{array}$ & $\begin{array}{c}\text { Treasury } \\
\text { Bills }\end{array}$ \\
\hline GSCI & 1.00 & & & & \\
S\&P 500 Index & -0.42 & 1.00 & & & \\
EAFE Index & -0.27 & 0.58 & 1.00 & & \\
Treasury Bonds & -0.32 & 0.42 & 0.20 & 1.00 & 1.00 \\
Treasury Bills & -0.20 & -0.08 & -0.31 & -0.05 & 1.00 \\
\hline
\end{tabular}

Source: Ibbotson Associates (1992).

Note: Monthly returns for January 1970 through April 1992.

deviations for the 1981-90 period for eight asset classes: stocks, small-cap stocks, foreign stocks, government bonds, corporate bonds, high-yield bonds, real estate, and futures (as represented by the Mount Lucas Management Index [MLMI]). Table 5 contains the correlation matrix.

Figure 3 is the minimum-variance set computed with (the light line) and without (the darker line) the MLMI. Again, futures contribute to portfolio

\section{FIGURE 2. Impact of Futures on Minimum-Variance Set with and without the GSCI}

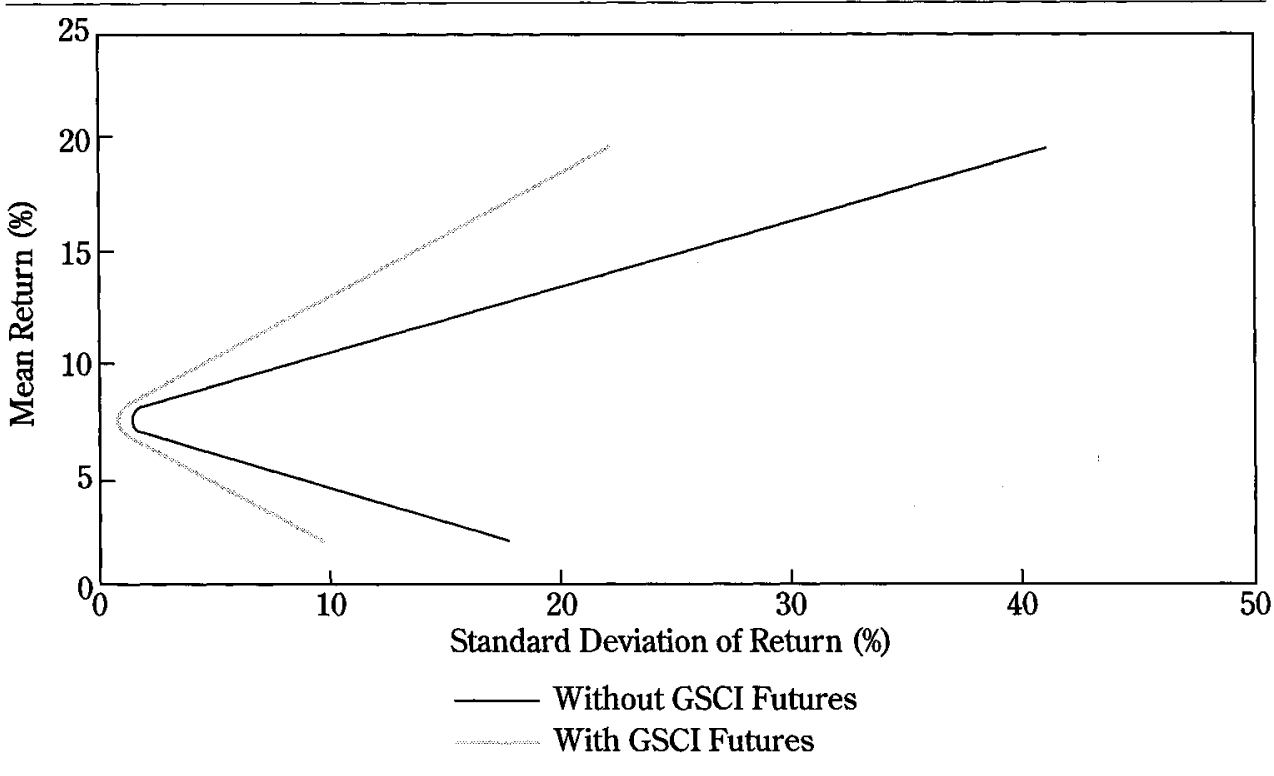

Data source: Chicago Mercantile Exchange.

Note: Asset classes are the GSCI, the S\&P 500 Index, the EAFE Index, T-bonds, and T-bills. 
TABLE 4. Summary Statistics for Elght Selected Asset Classes

\begin{tabular}{lcc}
\hline Asset Class & $\begin{array}{c}\text { Mean } \\
\text { (percent) }\end{array}$ & $\begin{array}{c}\text { Standard } \\
\text { Deviation } \\
\text { (percent) }\end{array}$ \\
\hline Stocks & 14.73 & 17.30 \\
Small-cap stocks & 11.57 & 22.61 \\
Foreign stocks & 14.69 & 18.00 \\
Government bonds & 13.94 & 13.63 \\
Corporate bonds & 14.09 & 12.31 \\
High-yield bonds & 12.73 & 9.68 \\
Real estate & 8.52 & 2.52 \\
MLMI & 14.64 & 7.58 \\
\hline
\end{tabular}

Source: Vannerson and Rudderow (1991).

Note: Monthly returns for 1981 through 1990.

efficiency. Although the reductions in the standard deviations are not as large as in the case with fewer asset classes, they are, nevertheless, significant.

In all cases, however, those discussed here and those reported in the literature, the correlations were computed over a fixed time period. Those correlations represent the best estimates of the expected relationship between futures returns and the returns on other asset classes. For any given future time period, the predicted relationships might not hold.

To understand the critical nature of this point, consider the moving average correlations between the returns on the CRB Index and the S\&P 500 Index and between the GSCI and the S\&P 500 that are presented in Figures 4 and 5 .

\section{TABLE 5. Correlation Matrix of the MLMI and Other Asset Classes}

\begin{tabular}{|c|c|c|c|c|c|c|c|c|}
\hline & Stocks & SS & FS & GB & $\mathrm{CB}$ & HYB & $\mathrm{RE}$ & MLMI \\
\hline Stocks & 1.00 & & & & & & & \\
\hline $\begin{array}{l}\text { Small-cap } \\
\text { stocks (SS) }\end{array}$ & 0.87 & 1.00 & & & & & & \\
\hline $\begin{array}{l}\text { Foreign } \\
\text { stocks (FS) }\end{array}$ & 0.84 & 0.73 & 1.00 & & & & & \\
\hline $\begin{array}{l}\text { Government } \\
\text { bonds (GB) }\end{array}$ & 0.41 & 0.25 & 0.40 & 1.00 & & & & \\
\hline $\begin{array}{l}\text { Corporate } \\
\text { bonds (CB) }\end{array}$ & 0.40 & 0.26 & 0.36 & 0.96 & 1.00 & & & \\
\hline $\begin{array}{l}\text { High-yield } \\
\text { bonds (HYB) } \\
\text { Real }\end{array}$ & 0.56 & 0.62 & 0.55 & 0.67 & 0.73 & 1.00 & & \\
\hline estate (RE) & -0.07 & 0.11 & -0.08 & -0.01 & -0.02 & 0.19 & 1.00 & \\
\hline MLMI & -0.23 & -0.16 & -0.31 & -0.17 & -0.05 & -0.13 & 0.26 & 1.00 \\
\hline
\end{tabular}

Source: Vannerson and Rudderow (1991).

Note; Monthly returns for 1981 through 1990. 
FIGURE 3. Impact of Futures on Minimum-Variance Set with and without the MLMI

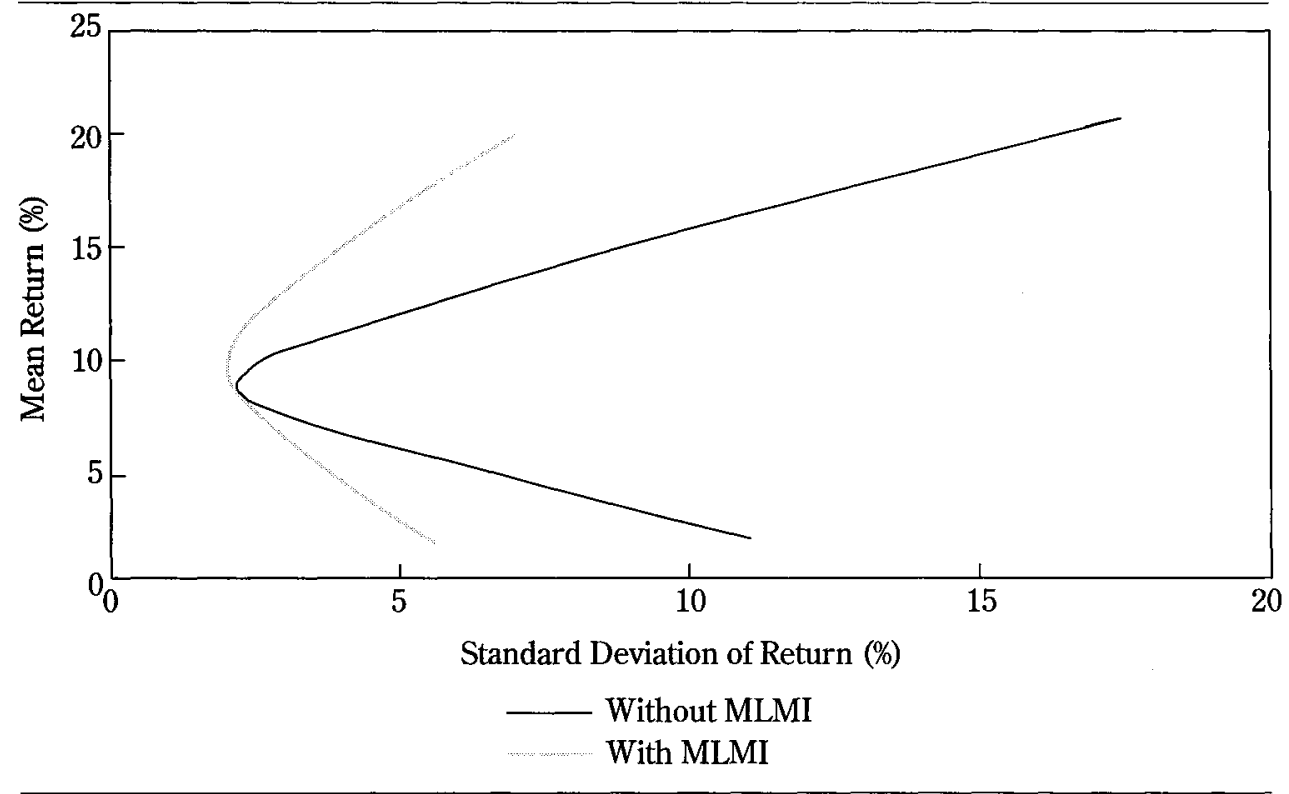

Data source: Mount Lucas Management.

Note: Asset classes are the MLMI, stocks, small-cap stocks, foreign stocks, government bonds, corporate bonds, high-yield bonds, and real estate.

The correlations were estimated on the basis of 12 months of data, starting in January 1971 (using the 1970 returns) and ending in December 1992.

In both cases, the relationship between the futures returns and the $S \& P 500$ Index returns is marked by considerable instability. In fact, the correlations are quite large and positive for extended periods. ${ }^{10}$ They are quite large and negative for other extended periods. When averaged for this long period, the overall correlation does tend to smooth out, which has led to the conclusion that not much of a relationship exists between futures returns and stock returns. These moving correlations raise some doubt about the benefits of managed futures and, at the least, force a careful consideration of whether the diversification benefits should be viewed as occurring, on average, over the long term.

An Inflation Hedge. The final argument to be considered is that man-

${ }^{10}$ The observation that the correlation is unstable has been made by many others. I am grateful to Matt Smith for pointing out this phenomenon. 
FIGURE 4. Twelve-Month Moving Correlation: S\&P 500 Index and CRB Indox Returns, 1971-92

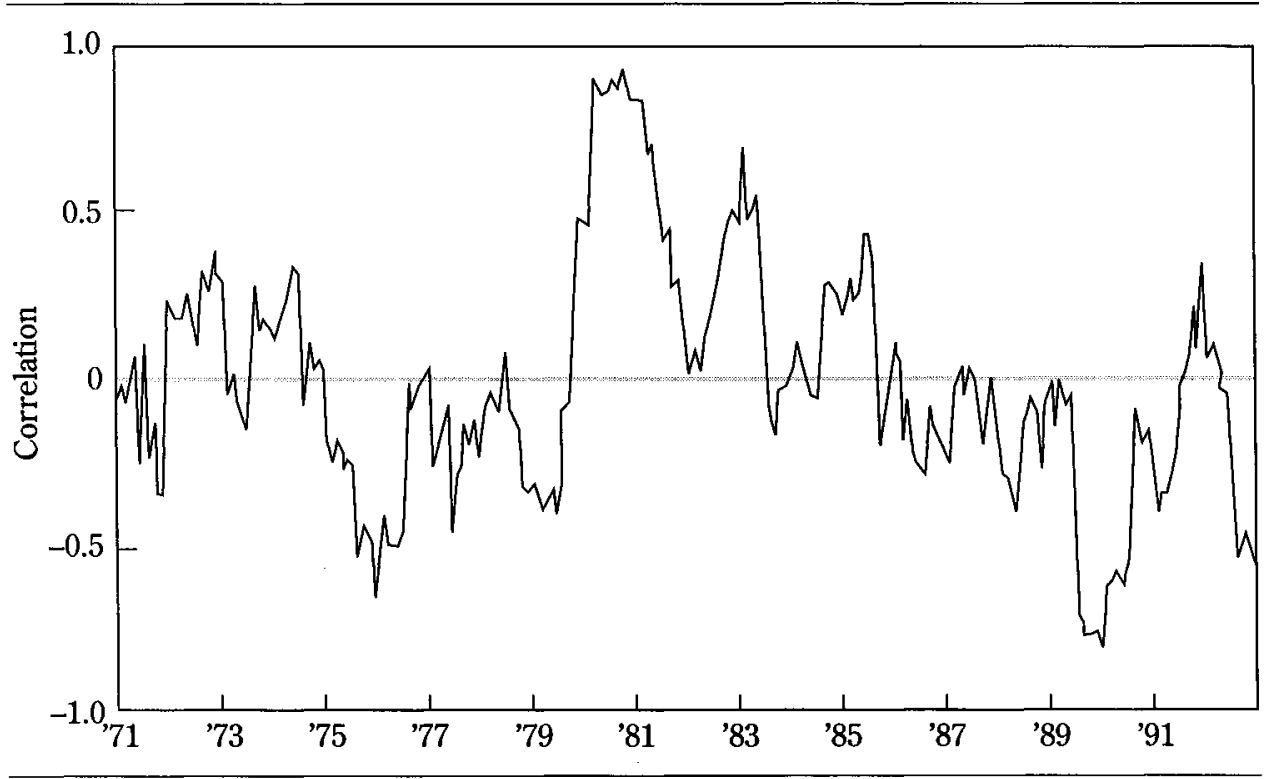

Data source: Chicago Mercantile Exchange.

aged futures may offer an opportunity to beat inflation. This hypothesis comes from the basic idea that commodity futures prices represent the values of the raw commodities used to produce consumer goods. Taking a position in these commodities, therefore, allows one to profit from increases in their prices.

Some evidence supports this hypothesis. Bodie (1983) examined the annual returns to futures during the 1953-81 period. He found that futures tend to perform well when inflation is high. The correlation with inflation, however, was only 0.247 . As a further look at this issue, consider the results presented in Table 6 for regressions of the inflation rate, as proxied by the Consumer Price Index, on the returns to the GSCI Total Return Index, the CRB Index, and the S\&P 500 Index (all separately). ${ }^{11}$

The GSCI is more closely related to the inflation rate than is the CRB Index. The regression slope coefficient on the GSCI is statistically significant $(t[\beta]>$ 2). However, the GSCI explains less than 2 percent of the variation in the inflation rate. That is, even though the GSCI is positively related to inflation

\footnotetext{
${ }^{11}$ The GSCI Total Return Index is the return on the GSCI after accounting for the interest that could be earned on the margin account.
} 
FIGURE 5. Twelve-Month Moving Correlation: S\&P 500 Index and GSCI Returns, 1971-92

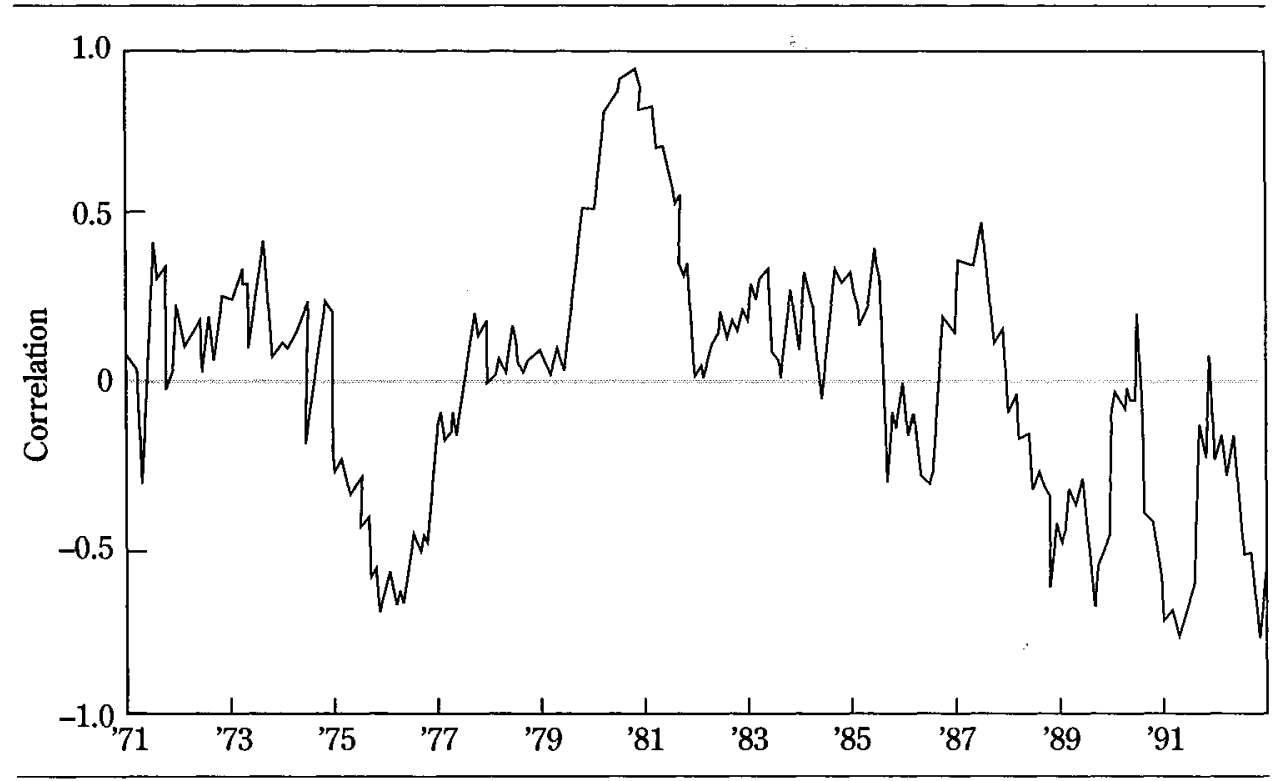

Data source: Chicago Mercantile Exchange.

and could be used as an inflation hedge, most of the variation in the inflation rate will derive from other sources. Thus, the GSCI would be a poor hedge.

The CRB Index fares even worse than the GSCI; it is statistically unrelated to the inflation rate. Interestingly, the S\&P 500 Index is significantly negatively related to the inflation rate; it explains more than 3 percent of the variation.

The case for futures as an inflation hedge is not, however, completely lost. Hanke and Culp (1992) showed that the CRB Index does have some power to

TABLE 6. Regressions of Percentage Change in Consumer Price Index on Percentage Change in GSCI, CRB Index, and S\&P 500

$(\% \Delta \mathrm{CPI}=\alpha+\beta[\% \Delta X]+e)$

\begin{tabular}{lccccc}
$\begin{array}{l}\text { Indepedent } \\
\text { Variable } \\
(\% \Delta X)\end{array}$ & $\alpha$ & $t(\alpha)$ & $\beta$ & $t(\beta)$ & \multicolumn{1}{c}{$\begin{array}{c}R^{2} \\
(\%)\end{array}$} \\
\hline GSCI & 0.004666 & 0.953 & 0.013066 & 2.346 & 1.97 \\
CRB Index & 0.004823 & 0.982 & 0.003552 & 0.454 & 0.06 \\
S\&P 500 Index & 0.004975 & 1.028 & -0.019630 & -3.069 & 3.34 \\
\hline
\end{tabular}

Notes: Monthly data for January 1970 through January 1992. The number of observations was 275 to 276. 
explain inflation rates when inflation is measured with a lag. In other words, changes in the CRB Index tend to precede changes in the inflation rate. Moreover, the relationship between futures prices and inflation is somewhat stronger when annual returns and inflation rates are used in the measurement. Ibbotson Associates (1992) reported a correlation of 0.26 between the annual GSCI returns and inflation rates, which would produce an $R^{2}$ of about 6.8 percent in a regression. The Chicago Mercantile Exchange (1992) reported that the GSCI, when annual returns were used, had a correlation with inflation of 0.55 for the 1970-90 period, 0.60 for the 1970-79 period, and 0.44 for the 1980-89 period. Thus, futures might not hedge the month-to-month variation in inflation rates but might provide some hedging benefits over a longer period, such as a year.

All of these results are based on a passive strategy of buying and holding futures, either the CRB Index or the GSCI, but evidence exists that actively managed futures programs may be more strongly correlated than passive strategies with inflation rates. Using annual returns for the 1975-85 period, Irwin and Landa (1987) found that futures funds had a correlation of 0.55 with the inflation rate whereas a buy-and-hold futures position had a correlation of 0.18 with inflation. Elton, Gruber, and Rentzler (1987), however, found that monthly futures fund returns during the 1979-85 period had a correlation with inflation of only 0.009 . These were fairly short periods characterized by hyperinflation, however, so the results may not be generalizable to a long period with volatile inflation rates.

\section{Disadvantages}

Managed futures also carry some disadvantages, namely, cost, volatility, questionable market capacity, and a negative image.

Costs. Any discussion of managed futures programs inevitably focuses heavily on costs. Managed futures are expensive, at least relative to the costs that investors typically incur when holding mutual funds. Most of the studies and articles about the fees associated with managed futures deal with the fees of public futures funds, but the private commodity pools and private contractual arrangements with commodity pool operators and CTAs must also be considered.

The cost components of futures funds are sales commissions, operating expenses, management fees, brokerage commissions, and incentive fees. Not all arrangements have all of these costs however, and the amounts vary widely.

Angrist and Tanouye (1992a) reported on these fees for six unnamed public funds. Sales commissions, which essentially correspond to the load charges 
found in stock and bond mutual funds, are not common. When they do appear, they are 2-3 percent. Some futures funds, like their stock and bond counterparts, charge exit fees. Operating expenses range from 1 percent to 2 percent. Management fees are 3-6 percent-quite large compared with the 1-1.5 percent commonly found in stock and bond mutual funds. Brokerage commissions as a percentage of equity range from 3 percent to 10 percent, which is consistent with a per-contract rate in the range of $\$ 10$ to $\$ 20$. Incentive fees run from 12 percent to 35 percent and are often based on performance relative to the previous high performance, as opposed to a benchmark. In some cases, all expenses must be covered before incentive fees are paid. Finally, the interest earned from cash equivalents is paid either to investors in the fund or to the fund's management. Overall fund fees tend to total 17-19 percent on average, but the most expensive funds can cost twice that amount.

These figures for public funds have been confirmed in several other studies. Irwin and Brorsen (1985), in their analysis of 20 public futures funds from 1975 through 1984 , found that commissions average 10.7 percent and management, incentive, and administrative fees average 8.5 percent. The overall average is thus 19.2 percent. Szala $(1989 \mathrm{~b})$ reported that expenses averaged 17.5 percent in 1988.

For private arrangements between institutional investors and futures managers, Irwin, Krukemeyer, and Zulauf (1994) reported that overall expenses average 10-12 percent, with most of the savings occurring through reduced brokerage commission rates. Management fees are in the range of 2.5 percent to 5 percent.

Cornew (1988) provided an extensive analysis of the fees of private commodity pools operating during 1981 and 1982 . Expenses averaged 38.8 percent and 46.5 percent during those two years, respectively. Out of this total, management fees were 6.9 percent and 7.8 percent and incentive fees were 0.9 percent and 3.8 percent. Commissions averaged 25 percent and 25.2 percent. Expenses were inversely related to pool size; pools of less than $\$ 500,000$ averaged more than 50 percent, whereas pools of more than $\$ 10$ million averaged about 20 percent.

When first confronted with these figures, most individuals are shocked. Managed futures trading does have high fees, but there are reasons. One is that most managed futures arrangements are based on relatively small amounts of invested funds. For example, in Cornew's study, the largest commodity pool was only $\$ 30$ million. In the Irwin-Brorsen (1985) study of 84 public futures funds, the average size of the funds in 1984 was only about $\$ 5$ million. Szala (1989b) reported an average size of $\$ 9.5$ million in 1988 , with the largest funds averaging about $\$ 80$ million. These figures are quite small 
relative to the size of mutual funds and result in a small base over which to spread the fund overhead.

As the industry grows, expenses are likely to come down. Szala (1989b) reported that the larger funds tend to have lower expenses and lower trading profits but higher investor returns. Vannerson and Schaumberg (1992) argued that the managed futures industry should strive to lower fees. They suggested that the management fee should be brought down to 0.8-1.5 percent, which would still leave it above the range for mutual funds, as it should be, in light of typical account sizes. They also noted that brokerage commissions range from $\$ 10$ to $\$ 100$ and that these should average $\$ 10$ to $\$ 15$.

Investors should be particularly sensitive to the different incentive fee arrangements. For example, suppose $\$ 1$ million is committed to a managed futures program in which two CTAs will each invest half the money. Suppose the incentive arrangement is that each CTA earns an incentive fee if he or she generates a profit. For the moment, ignore all other costs. Suppose one CTA earns 1 percent and the other loses 1 percent. The fund's gross trading profit is zero, but the net profit is negative because one CTA earned an incentive fee and the other did not. An alternative arrangement is that no CTA earns an incentive fee unless the fund makes an overall profit, but this arrangement removes some of the incentive itself because a given CTA knows that his or her outstanding performance could be diluted by poor performance by another CTA. One way to offer incentives and yet control fees is to require that any CTA who loses money can never earn an incentive fee unless all accumulated losses have been recovered. In other words, the incentive fee earned by a CTA in a given period is not paid unless the value of the funds committed to that CTA has grown since the initial deposit.

Finally, the costs of managed futures trading must be put in proper perspective. Consider an investment of $\$ 1$ million in a managed futures arrangement that has a high ( 30 percent) expense ratio. This expense ratio does not include incentive fees, which will be accounted for separately. How well would the fund need to perform during a three-month period to cover the costs?

Start with the following assumptions:

- The CTA deposits 70 percent of the available funds in a money market fund paying 1 percent interest during the three-month period.

- The remaining funds are used as margin deposits to support as many futures contracts as possible. The margin account pays no interest, although this assumption could be changed.

- The CTA takes a long position in an S\&P 500 futures contract that expires in three months. The current futures price is 452.65 . The margin requirement is $\$ 9,000$. 
- Half of the expenses are taken out at the beginning of the period, and half are taken out at the end of the period. The expense ratio is $0.30 / 4$ $=0.075$, for three months.

- The CTA receives an incentive fee of 15 percent if she makes any profit over the period. 12

Thus, the CTA will withdraw $\$ 1,000,000(0.075 / 2)=\$ 37,500$ up front to cover expenses, leaving $\$ 962,500$. She will deposit 70 percent of this money $(\$ 673,750)$ in cash equivalents earning 1 percent interest. The remaining $\$ 288,750$ will be used to take a position in 32 S\&P 500 futures contracts $(\$ 288,750 / \$ 9,000=32.08)$.

At the end of the three-month period, the cash equivalents will be worth $\$ 680,488$. Then, the CTA will withdraw the remaining expenses, $\$ 37,500$. If the futures price does not change during the quarter, the investor will have $\$ 680,488-\$ 37,500+\$ 288,750=\$ 931,738$. In order to break even, a profit of $\$ 80,309$ is needed ${ }^{13}$ which requires that the $S \& P$ move from 452.65 to 457.66 , a gain of 1.11 percent. ${ }^{14}$ In other words, if the market moved up at an annual rate of only about 4 percent, the investor would break even. If the investor were able to talk the CTA out of the 15 percent incentive fee, the S\&P would need to move up only 0.94 percent to cover the $\$ 68,263$ in costs.

Of course, this example presumes that the CTA guesses correctly on the direction of the market. Moreover, the investor would need to consider the interest earned on the futures margin (which would lower the breakeven) and a risk premium. If no trading profit on the futures position resulted in either case, the investor would lose about 6.8 percent. Keep in mind that the rate is a three-month rate.

The example is not meant to demonstrate specific possibilities but only to indicate that the requirements for profiting in the face of what appear to be large costs are not necessarily unrealistic. Moreover, the example includes a high incentive fee and expense ratio.

The example demonstrates that recovery of costs is accomplished with fairly small price moves. The key is guessing correctly the direction of the market. In most cases, however, a large number of different commodities are being

\footnotetext{
${ }^{12}$ This incentive fee is high. Some arrangements pay incentives only if returns exceed some minimum level, such as the highest return previously earned -in other words, the net new profit. A stringent arrangement is used here to create a demanding test. The assumption is that this account is new, so any profits are new.

${ }^{13}$ Out of $\$ 80,309$, the CTA would receive 15 percent, or $\$ 12,046$, leaving about $\$ 68,263$.

${ }^{14} \mathrm{With}$ a multiplier of $\$ 500$, the profit for a move from 452.65 to 457.66 would be approximately the $\$ 80,000$ necessary to break even.
} 
traded, which means that losses in some markets can be offset by gains in another. In any case, a small net gain will generally cover costs.

Volatile Performance. The performance of all professional investment managers is subject to fairly high volatility. Even mutual fund managers do not typically perform consistently. Some have argued that futures managers are, perhaps, even more inconsistent. The evidence on this point is provided in several papers that are discussed in Chapter 4.

Market Capacity. The futures market is large and liquid, but some individuals have nevertheless expressed concern that the volume of managed futures trading might place pressure on the futures markets, particularly given that many CTAs use similar technical trading models. Lukac, Brorsen, and Irwin (1988) examined this issue but found no evidence that the direction of trading is so similar that it is likely to have an effect on the market. In any case, the extent to which futures managers could move the market is no greater than that of institutional stock and bond managers.

Negative Image. The futures markets do suffer from a negative image. Although the tradition is to blame many of the security market woes on futures speculators, the real problems, which are not the topic of this monograph, lie elsewhere. Nevertheless, the negative image of futures markets is not an insignificant factor, because it exacerbates the problem of convincing executives and trustees to try a managed futures program. Chapter 7 addresses this point again in the discussion of how to set up a managed futures program. 


\section{The Performance of Managed Futures}

Probably the most important question to be examined in this monograph is whether managed futures programs are likely to offer attractive returns relative to their risks. This chapter reviews the major studies that have looked at the returns to managed futures. Many of these studies examined return and risk but did not address the issue of whether the returns are sufficient compensation to justify the risk. That issue, even for investment arrangements that are less complicated than futures funds (such as equity and fixed-income portfolios), is complex enough to require its own chapter and is the subject of Chapter 6. This chapter simply takes a look at what the studies have concluded.

The question of how managed futures perform lends itself to two general areas of inquiry: what are the returns and risks of managed futures, and how consistent are the returns and risks from period to period. About a dozen studies have examined the returns and risks of managed futures. Some studies looked at how public funds perform, some looked at how private pools perform, and some examined the performance of individual commodity trading advisors (CTAs).

\section{The Returns and Risks of Managed Futures}

Lintner's highly publicized study (1983) considered the potential for managed futures to improve portfolio efficiency. Lintner analyzed data on 8 public funds and 15 CTAs for the period from July 1979 through December 1982. Lintner found the average return on the funds during the period to be a little more than 2 percent a month and the average standard deviation to be about 9.6 percent a month. Combining the 8 funds into a single equally weighted portfolio left the average return the same but lowered the standard deviation to about 6.3 percent. The 15 CTAs generated an average return of 2.7 percent, an average standard deviation of 12.4 percent, and a portfolio standard deviation of 7.3 percent.

As a comparison, Lintner computed the returns to a stock portfolio (the 
Center for Research in Security Prices portfolio), a bond portfolio (the Salomon Brothers Index), an index of 60 percent stocks and 40 percent bonds, and Treasury bills. The stocks earned 1.4 percent with a standard deviation of 5 percent. The bonds earned 0.7 percent (standard deviation, 5.2 percent). The 60/40 portfolio earned 1.1 percent (standard deviation, 4.3 percent), and Treasury bills earned 0.9 percent (standard deviation, 0.2 percent).

The first thing to note is that the characteristic risk-return trade-off of stocks in relation to bonds is not present. That is, stocks are expected to have a higher return as well as higher risk than bonds, but stocks actually had lower risk. This result occurs because the period was fairly short and the normal risk-return trade-off is present only over the long run. Thus, Lintner's findings should be viewed with caution.

Nevertheless, the risk-return relationship between managed futures and stocks is observed regardless of whether individual CTAs or public futures funds were used in the test. Whether the individual CTAs are to be preferred to funds is not clear, because the risk-return relationship of the CTAs to the funds is as expected. Unless one could identify the funds or CTAs with the best risk-reward trade-off, a combination of all of them would be best.

Irwin and Brorsen (1985) examined the performance of 84 public futures funds for 1975 through 1983, a somewhat longer period than in Lintner's study and a period that included rapid growth in the offering of public futures funds. Irwin and Brorsen found that the average annual fund return was 9.8 percent during the period and the average standard deviation was 23.1 percent. The cross-section of returns was quite variable; many of the funds generated large negative returns, and one was wiped out completely. As noted in Chapter 3, these authors found that costs exacted a heavy toll on returns.

Irwin and Landa (1987) examined the performance of a passive futures strategy (the Commodity Research Bureau [CRB] Index) and an index of futures funds, which was not specifically identified, as well as the performance of Treasury bills, Treasury bonds, stocks (the S\&P 500 Index), real estate, and gold. They used only annual data for the $1975-85$ period, so the sample is very small. The CRB Index generated an average annual return of -4.9 percent with a standard deviation of 11.5 percent; the futures fund index generated an average return of 9.9 percent (standard deviation, 22.9 percent). In comparison, stocks earned 9.5 percent (standard deviation, 14.7 percent).

Although one could conclude from this study that futures are a poor investment, T-bonds also performed badly, with a return of 2.9 percent and a standard deviation of 16.3 percent. Should T-bonds be dismissed as an investment class because their average return is lower and standard deviation higher 
than those of stocks? ${ }^{1}$ Once again, the time period is too short to reveal the normal risk-return relationship between stocks and bonds. Consequently, not much significance should be attached to the fact that futures earned about the same as stocks but with significantly greater risk.

Murphy (1986) examined the monthly figures for the performance of 11 public futures funds during the period of May 1980 through April 1985. He found that only one fund outperformed the S\&P 500 Index. The average fund earned 0.8 percent, and the average standard deviation was 5.9 percent. The S\&P 500 Index average return was 1.4 percent (standard deviation, 4.1 percent); T-bills earned 0.8 percent (standard deviation, 0.2 percent). Futures funds were again inferior to stocks because of a lower return and higher risk, but in this study also, the time period is short. The risk-return trade-off between stocks and T-bills is appropriate, but no bond returns were tested, so one cannot tell whether the time period was sufficiently long to represented a "normal" stock-bond relationship in the market.

Irwin, Krukemyer, and Zulauf (1994) examined the performance of all public funds for which they could obtain monthly data for 1979 through 1990 . The number varied from 10 to 186 . For the full period, the average return was 1.2 percent with an average standard deviation 9.6 percent. A portfolio of public funds had a standard deviation of 6.4 percent. Stocks earned 1.3 percent (standard deviation, 4.7 percent); small-capitalization stocks earned 1.3 percent (standard deviation, 5.7 percent); T-bills earned 0.7 percent (standard deviation, 0.2 percent); intermediate-term government bonds earned 0.9 percent (standard deviation, 2.2 percent); long-term government bonds earned 0.9 percent (standard deviation, 3.9 percent); and long-term corporate bonds earned 0.9 percent (standard deviation, 3.6 percent). With the exception of the small-cap stocks versus stocks in general, these return figures fit the expected risk-reward trade-offs. Futures funds, therefore, do not seem to offer a higher return for their higher risk. Ignoring for the moment the possibility of using both futures and stocks, these results indicate that an investor could clearly do better in stocks.

Elton, Gruber, and Rentzler (1987) examined the monthly returns on public futures funds for the period of June 1979 through June 1985. The number of funds varied from 12 to 85 , and the average return was 0.7 percent (standard deviation, 11.3 percent). During the same period, stocks earned 1.31 percent (standard deviation, 4 percent), small stocks earned 1.7 percent (standard

\footnotetext{
${ }^{1}$ Irwin and Landa also found that T-bills earned 1.6 percent (standard deviation, 3.5 percent), real estate earned 3.2 percent (standard deviation, 2.9 percent), and gold earned 3.7 percent (standard deviation, 38.8 percent).
} 
deviation, 4.7 percent), long-term corporate bonds earned 0.8 percent (standard deviation, 4.3 percent), long-term government bonds earned 0.8 percent (standard deviation, 0.4 percent), and T-bills earned 0.9 percent (standard deviation, 0.2 percent). Thus, futures funds had relatively high risk with little return. Again, however, this time period is quite short.

In a follow-up study (1990), the authors examined the eight-year period from 1980 through 1988 . The average fund earned 2.3 percent a year during the period and had a monthly standard deviation of 10.4 percent. The figures for alternative asset classes were: stocks, 14.9 percent (standard deviation, 4.9 percent); long-term corporate bonds, 11.8 percent (standard deviation, 3.8 percent); long-term government bonds, 11.4 percent (standard deviation, 4.2 percent); the Shearson Lehman Bond Index, 11.4 percent (standard deviation, 2.4 percent); and T-bills, 8.6 percent (standard deviation, 0.3 percent). Thus, this period was characterized by fairly normal risk-return trade-offs, yet futures funds fared poorly.

Most of the studies reported so far considered only public futures funds, but what of the performance of private arrangements? Baratz and Eresian (1986) examined the performance of 12 CTAs during 1980 through 1985. The average monthly return was 2.7 percent, and the average standard deviation was 12.8 percent. During that same period, the S\&P 500 earned 0.9 percent (standard deviation, 4.3 percent) and long-term T-bonds earned 1.1 percent (standard deviation, 4.3 percent). Therefore, during this limited period, these futures managers earned large returns but also incurred high risks. Stocks did not beat bonds during this period, however, so whether the period would be considered normal is difficult to determine.

Schneeweis, Savanayana, and McCarthy (1991) examined the monthly returns to the Managed Accounts Reports (MAR) equally weighted CTA Index and Dollar-Weighted CTA Index, an index of private pools, an index of public funds, the S\&P 500 Index, a small-cap stock index, government bonds, and corporate bonds for the $1980-88$ period. The equally weighted CTA Index earned an average monthly return of 2.1 percent with a standard deviation of 8 percent; the Dollar-Weighted Index earned 1.9 percent (standard deviation, 7.4 percent). The pools earned 1.6 percent (standard deviation, 6.7 percent); the funds earned 0.8 percent (standard deviation, 6.5 percent). In comparison, the S\&P 500 Index earned 1.4 percent (standard deviation, 4.9 percent), small-cap stocks earned 1.5 percent (standard deviation, 5.8 percent), government bonds earned 1 percent (standard deviation, 4.2 percent), and corporate bonds earned 1.1 percent (standard deviation, 3.9 percent).

Thus, this period seems to have been characterized by a fairly normal risk-return trade-off, with stocks having higher returns and higher risks than 
bonds. Both indexes of CTAs beat stocks but had higher risk, and whether the additional return justifies the additional risk is not clear. Nevertheless, the fact that higher returns are associated with the higher risk of this type of investing over a reasonably long (eight-year) period is encouraging.

Schneeweis, Savanayana, and McCarthy (1992) also examined the monthly returns to 14 CTAs from January 1982 through October 1987 . They combined the 14 CTAs into a single portfolio, called the Multi-Manager Portfolio. For comparison, they also looked at the returns on the MAR equally weighted CTA and Dollar-Weighted CTA indexes, the pool index, and the fund index as well as the S\&P 500 Index and a bond index.

The Multi-Manager Portfolio earned an average monthly return of 1.7 percent (standard deviation, 5.2 percent). The equally weighted CTA Index earned 1.3 percent (standard deviation, 6.9 percent), and the Dollar-Weighted CTA Index earned 1.2 percent (standard deviation, 6.3 percent). The pool index earned only 0.9 percent (standard deviation, 6.2 percent), and the fund index earned 0.3 percent (standard deviation, 6.4 percent). In comparison, the S\&P 500 Index earned 1.3 percent and had a standard deviation of 5.2 percent. A bond index earned 1 percent (standard deviation, 3.7 percent).

These results show a normal trade-off between stocks and bonds and can thus be considered somewhat representative of a normal period, in spite of the period being only five years. Note that despite the poor performance of funds and pools, the Multi-Manager Portfolio earned a higher return than the S\&P 500 Index with comparable risk. The equally weighted and Dollar-Weighted CTA indexes earned a return similar to the S\&P 500 Index, however, with higher risk. These results are in some contrast to the previous study by the same authors, but the differences may simply reflect the different time periods. Although the performance of the 14 CTAs examined was clearly excellent, whether one could in the future identify who the best 14 CTAs would be for a given five-year period is not obvious.

Schneeweis-Savanayana-McCarthy obtained even better results, however, when they followed a simple selection rule. They ranked the 14 CTAs from highest return to lowest in a given year and chose the 10 best performers. Then they measured those top performers' returns for the following year. The average was 2.3 percent with a standard deviation of 5.1 percent.

Szala (1989b) reported on a study of 690 private pools and funds for 1988. Although the time period is extremely short, the study is quite comprehensive in including so many traders. The unweighted average return was 2.8 percent, and the weighted-average return was 17.2 percent, which indicates that the large firms were much more profitable than the small ones. No figures were given for the risk. 
Cornew (1988) reported the performance of all private commodity pools during the years 1981 and $1982 .{ }^{2}$ The performance of these pools was extremely poor. In 1981 , only 33 percent were profitable; the average return was -38.5 percent. In 1982 , only 37 percent were profitable, with an average return of -21 percent. Of course, this time period is also very limited.

In summary, most of the studies of managed futures performance cover a fairly limited time period. The studies that do encompass a longer period generally demonstrate a positive risk-reward trade-off; that is, more risk is generally associated with more return. Pool and fund performance is typically poor-a result, no doubt, of the high expenses. The performance of CTAs measured individually shows much better performance than the pools and funds. Therefore, an important consideration in adding futures to a portfolio is being able to identify the best managers or, at least, being able to combine all of them into a single multiple-manager arrangement. Although this task is clearly not simple, this consideration may help to explain why multimanager portfolios have become the current wave.

\section{The Consistency of Managed Futures Returns}

Now consider the consistency of performance. Irwin, Ward, and Zulauf (1992) examined the returns of 363 CTAs for the 1979-89 period. CTAs who ceased operations during this time were included up until they dropped out, at which time, the money was allocated to T-bills. The authors examined how the returns, standard deviations, and correlations with stock and bond indexes changed from period to period and found virtually no correlation between returns from one two-year period to the next. They found a slight correlation between volatility from one period to the next, but the relationship was not strong. The correlation between stock and bond indexes and the CTA returns was also inconsistent from one period to the next.

Several studies have reported on how the returns advertised in the prospectuses of newly created funds and pools correlate with the returns generated after the funds or pools went public. Edwards and Ma (1988), for example, examined public funds that used a single CTA during the fairly limited period of 1985 through 1987. They found an average prepublic return of almost 50 percent but a negative average postpublic return.

Elton, Gruber, and Rentzler (1989) examined the information in public funds' prospectuses for 77 funds. The average monthly return before a fund went public was 5.6 percent; the average after going public was 0.2 percent for

\footnotetext{
2The Cornew sample did include a few public pools, but it was composed mostly of private pools.
} 
the first year, 0.4 percent for the first two years, 0.3 percent for the first three years, and 0.5 percent for the first four years. The prepublic fund returns did not reflect the fees incurred after the funds went public, but the authors recalculated the prepublic fees to reflect public fund fees and found that the differences, although smaller, were still significant. They also found that many pool operators chose to report returns for long prepublic periods if doing so improved their performance reports.

Irwin (1994) examined this issue for 36 public funds for the 1980-89 period. The postpublic returns exceeded the prepublic returns for only 7 funds. The average prepublic annual return was almost 50 percent, whereas the average postpublic annual return was about 11 percent. The correlation was only 0.075 .

These studies raise an important issue for investors who are considering managed futures. The Commodity Futures Trading Commission requires that at least three years of performance history, if available, be presented in a prospectus. Irwin argued that this requirement misleads the public into believing that past performance is indicative of future performance, which is not true. ${ }^{3}$ He suggested that the prospectus include the performance of an index of public funds for the previous three years. The historical data on the CTA could still be included, but the index information would make clear that the average CTA does not perform as well as the CTA who, after a possibly brief period of strong performance, chooses to open a pool or fund. Elton, Gruber, and Rentzler (1989) added that the statement of returns should include an estimate of costs and that a statement should be provided indicating that 36 months of data are required and that additional return data are provided at the discretion of the fund operator. These suggestions would go a long way toward full and unbiased disclosure.

Most institutional investors will not be dealing with futures funds, but many of the CTAs with whom they might work could manage such funds. These institutions need to be aware that, although the returns on funds and private pools are heavily laden with costs that might be much lower in private arrangements, the inconsistency from period to period is fairly certain. Thus, institutions considering a managed futures program should be wary of those CTAs that heavily promote recent remarkable performance, which may be merely a brief snapshot of performance from a highly volatile return distribution.

Inconsistency, however, is no more of an indictment of managed futures traders than it is of any other group of investment managers. The evidence is

\footnotetext{
${ }^{3}$ The simple statement that "past performance may not be indicative of future performance" is seldom adequate warning.
} 
weak that bond and stock managers show much interperiod consistency. The real questions are whether managed futures offer a reasonable trade-off between risk and return and whether they provide diversification benefits. In the studies to date, the evidence looks promising. 


\section{Evaluating the Performance of a Managed Futures Program}

Performance evaluation in general is an extremely complex and controversial subject. The livelihoods of many, if not most, portfolio managers depend on how the managers look in an ex post analysis of the performance of their portfolios. Many issues, such as the choice of an appropriate benchmark, the time period over which performance is to be measured, and the precise measurement of returns, merit detailed discussions themselves. These and other issues are not unique to managed futures. They are confronted whenever any portfolio, whether it includes managed futures or not, is evaluated. The reader can consult Association for Investment Management and Research (1991) and Bodie, Kane, and Marcus (1993) for detailed treatments of the current recommendations with regard to many of these issues.

The concern in this chapter is how specifically to evaluate a managed futures program. In addition to touching on the critical issues in an evaluation of any investment program, the chapter will discuss the commonly used criteria and present a simple framework for performance evaluation. Keep in mind that the framework may not be the best specific method for every situation; the issue is complex, and each firm should evaluate its situation individually.

\section{Measuring Returns}

The controversy surrounding the actual measurement of returns is partly a result of the effect of intraperiod cash flows. In a portfolio, additional funds are deposited from time to time and funds are at times withdrawn. Suppose the portfolio is to be evaluated monthly but funds are deposited about the middle of the month. In this case, the market value of the account at the end of the month will reflect the accumulated investment value of the original funds as well as any investment earnings on the funds that were in the account only half a month. The final total obviously cannot be expressed relative to the total at the beginning of the month. What is the correct rate of return? 
For example, suppose $\$ 1$ million is invested on March $1, \$ 250,000$ is added on March 15, and the final value of the portfolio on March 31 is $\$ 1,268,000$. The many suggested ways of measuring the rate of return for such a portfolio lead to slightly different answers, but in actuality, only one answer is correct. Obtaining that answer requires that one know the value on March 15 of the dollars that were deposited on March 1. Suppose that figure is $\$ 1,007,500$. Then the fund earned 0.75 percent (that is, $[\$ 1,007,500 / \$ 1,000,000]-1)$ for 15 days. Then, on March 15 , the fund balance became $\$ 1,257,500$ (that is, $\$ 1,007,500+\$ 250,000)$. At the end of the month, the balance was $\$ 1,268,000$. So, for the next 16 days, the fund earned 0.835 percent (that is, $[\$ 1,268,000 / \$ 1,257,500]-1)$. Thus, the monthly rate of return was 1.591 percent (that is, [1.0075] $\times$ [1.00835] - 1). In other words, a dollar invested at the beginning of the month was worth $\$ 1.01591$ at the end of the month. To be precise, a fund must be able to obtain its market value at any time it has inflows or outflows.

Mutual funds, which ordinarily have daily cash inflows and outflows, handle the measurement problem by defining a net asset value. Dividing the fund value by the number of shares automatically accounts for inflows and outflows. For many institutional portfolios, particularly those that deal in somewhat illiquid assets, such as real estate, obtaining good market-value information every day is difficult. Thus, they sometimes assume that fund flows occur at the beginning, end, or middle of the month, or sometimes assume that the funds flow evenly throughout the four-to-five weeks of the month. All such approximations result in slightly inaccurate return figures, but because the bias can go in either direction, an investor should not assume that the returns are consistently overstated.

These problems certainly exist for managed futures programs. The Commodity Futures Trading Commission (CFTC) requires that, for reporting purposes, all additions and withdrawals be assumed to occur at the end of the month. In the preceding example, the rate of return would be 1.8 percent (that is, $[(\$ 1,268,000-\$ 250,000) / \$ 1,000,000]-1)$. In other words, the returns earned by the additional dollars at work from March 16 through March 31 would be counted as gains, but the increase in the investable base would not be counted. If one treated the additions or withdrawals as occurring at the beginning of the month, the example fund's monthly return would be $(\$ 1,268,000) /(\$ 1,000,000+\$ 250,000)-1=0.0144$, or 1.44 percent. The earnings from the funds would be counted but would be treated as if they had accumulated over the entire month.

Fortunately, the daily marking-to-market process in futures facilitates a reasonably accurate statement of managed futures returns. Every day, the 
futures clearinghouse, marking each account to the current market price, adds or withdraws gains or losses. Thus, every day, a CTA knows how much cash he or she has in the margin account. The remaining funds are invested in cash equivalents, which can be valued each day. Therefore, in contrast to the case of ordinary mutual funds or institutional securities portfolios, the total value of the dollars under management in a futures account can always be easily determined.

\section{Traditional Measures of Managed Futures Performance}

Several popular measures of performance are used by the managed futures industry, and as with sports statistics, a single measure seldom captures all aspects of performance. In addition, no special value of these ratios indicates quality performance; the ratios are used primarily for comparative purposes in ranking CTAs.

The Sharpe ratio (Sharpe 1966) is a measure of the risk premium earned per unit of risk. It is defined as follows:

$$
\text { Sharpe ratio }=\frac{\text { Return }- \text { Risk-free rate }}{\text { Standard deviation }} .
$$

The Sharpe ratio is a simple measure designed to indicate the return per unit of risk. It is technically correct only for portfolios that lie on the efficient set. If the portfolio is not efficient, which will probably be the case for most managed futures portfolios, the ratio loses some of its theoretical soundness; its interpretation as a measure of return per unit of risk, however, remains intact.

In using the Sharpe ratio to evaluate managed futures, it might be advisable to not subtract the risk-free rate. The purpose of subtracting the risk-free rate is to indicate that funds not invested could be earning interest; in the case of managed futures, all funds are generally earning interest. The industry does, in fact, use this variation of the Sharpe ratio, which it calls the efficiency index.

The managed futures industry, and the investment industry as a whole, often evaluates performance by looking at the maximum drawdown. A drawdown is simply a loss incurred after reaching a high. Each time a new high is reached, a potential drawdown starts. The drawdown continues until the low is reached. The maximum drawdown is simply the largest of these "losses" during a period of time.

Comparing losses that span different time periods, however, is inappropriate. For example, suppose a manager experiences a 5 percent loss during one week in a six-month period. During the next six-month period, the same 
manager reaches a peak at the beginning of the period and falls steadily to a trough at the end of the period, with the loss being 10 percent. The maximum drawdown for the year will be 10 percent, but the 5 percent loss in one week is far more significant and may be indicative of unusually high volatility. Although the drawdown figure certainly contains information, it should be used only in conjunction with other measures of performance.

Another commonly used performance measure is the Sterling ratio, defined as follows:

$$
\text { Sterling ratio }=\frac{\text { Average annual return over past } 3 \text { years }}{\text { Maximum drawdown }}+0.1 .
$$

This ratio is simply an ad hoc measure of return to variability.

Perhaps the most common way of ranking CTAs is by simple rate of return, which is not, of course, adjusted for risk. If the rate of return is measured properly and compounded over many periods, it can be viewed as a geometric mean, which can be an appropriate measure of risk-adjusted returns. ${ }^{1}$ It is affected by the volatility of the returns and, therefore, makes something of its own risk adjustment. In addition, the geometric mean is consistent with investors whose utility is of the logarithmic form. ${ }^{2}$ As a measure of performance, the geometric mean rewards return and penalizes risk.

Sometimes, one will see a slight variation of the geometric mean called the Value-Added Monthly Index (VAMI), which is the value at a given point in time of $\$ 1,000$ previously invested. The VAMI will differ from the original $\$ 1,000$ by the geometric mean, compounded over the number of months. Unfortunately, most reported returns are probably not being expressed as geometric means. Often, the performance ranking is based on how a given CTA did during a month. Without a multimonth analysis, one is simply rewarding return without penalizing risk. ${ }^{3}$

\footnotetext{
${ }^{1}$ For example, suppose a CTA earns returns of +2 percent, -4 percent, +7 percent, and +3 percent for four quarters. The annual return is 7.9 percent (that is, $[1.02] \times[0.96] \times[1.07] \times$ [1.03] -1). The geometric mean quarterly return is 1.9 percent. If the return is expressed as $(0.02-0.04+0.07+0.03) / 4=0.02$, the result is the arithmetic mean, and by itself, it is not appropriate as a risk-adjusted performance measure.

${ }^{2}$ Logarithmic utility means that the utility of, say, $\$ 100$ is $\log _{\mathrm{e}} 100=4.61$ utils. Logarithmic utility has many of the desirable properties that characterize rational investor behavior.

${ }^{3}$ Of course, most rankings do provide risk measures together with the returns, but these measures are often not incorporated in the rankings.
} 
Many industry newsletters and information services provide rankings of CTAs that incorporate some of the measures noted here. ${ }^{4}$ Some, such as the Barclay Managed Futures Report and Managed Accounts Reports, have developed their own measures. In addition, such simple measures as worst-month return or best-month return are used, and CTAs are sometimes sorted into volatility groups and ranked by returns within a given group.

\section{A Managed Futures Benchmark}

Comparing returns against a benchmark portfolio is typically an important part of any performance evaluation. Equity portfolio managers commonly speak of "beating the S\&P 500," for example, and are often rewarded for doing so. In many cases, no adjustment is made for the additional risk they might be taking to earn the extra return. Of course, the S\&P 500 Index is not really broad enough to serve as the true market portfolio, but it may be a reasonable proxy if the securities available to the manager are largely drawn from those 500 stocks.

The managed futures industry has increasingly concerned itself with the development of benchmarks and indexes. Appendix A discusses some of those. Recall that the Goldman Sachs Commodity Index (GSCI) and the Commodity Research Bureau (CRB) Index are indexes of passive futures trading. They reflect the returns from simple long positions in various commodities. They do not include financial or currency futures.

The Barclay and Managed Accounts Reports indexes are measures of the performance of actual CTAs. They can be thought of, somewhat loosely, as the average performance of a CTA.

The Mount Lucas Management Index is an active index, but it does not reflect the returns to real CTAs. Rather, it attempts to simulate the returns from a simple technical trading rule.

A good benchmark should reflect the universe of investment opportunities actually available to the manager being evaluated. However, under that criterion, there is actually no satisfactory benchmark for managed futures. The GSCI and the CRB Index are measures of the performance of a passive strategy of holding various nonfinancial and noncurrency futures. They might be useful measures to help determine whether the managed futures industry as a whole had performed well. However, to evaluate a given CTA or group of CTAs, an appropriate benchmark would seem to be one of the indexes of active CTAs. The use of this type of index would serve to answer the question of whether the chosen CTA or CTAs outperformed the average CTA. This

\footnotetext{
${ }^{4}$ See Appendix B for information on some of the newsletters.
} 
benchmark would not strictly meet the test that the average performance of CTAs as a whole could have been earned by simply choosing a kind of "market portfolio" of CTAs. Currently, such an arrangement is not available; however, when the capital asset pricing model first suggested the use of the market portfolio as a benchmark, there were no index funds. Today, there are quite a few.

As Roll (1978) has pointed out, the choice of a benchmark portfolio completely determines performance. Two seemingly similar portfolios can completely reverse the rankings of a group of managers. This issue is an important one that applies to all areas of investments.

\section{A Framework for Performance Evaluation}

The simple system developed in this section is intended for evaluating the performance of an institutional portfolio that combines a position in a traditional securities portfolio with managed futures. This system, however, does not solve all the problems of performance evaluation discussed in this chapter. Moreover, it must be implemented with care; the example used here is a very basic one.

Suppose the manager of an institutional portfolio of $\$ 1,000,000$ decides to allocate 20 percent to a managed futures program through a single CTA. Assume that the manager evaluates the program's performance at the end of a two-year period. ${ }^{5}$ At the end of the two-year period, the quarterly data he has collected indicate that the overall portfolio is worth $\$ 1,119,193$. Was this performance good? The program earned 11.92 percent during a two-year period, an annual return of 5.79 percent. This figure may at first seem low, but the manager must look more closely.

First, recall that 20 percent of the portfolio is allocated to the CTA, so 80 percent is allocated to the securities portfolio manager. The securities component of the portfolio will be called the "active" portfolio. The manager needs to know the quarterly returns on the active portfolio and the quarterly returns on the managed futures component of the portfolio.

In addition, he needs two benchmarks. The first, which will be considered the "passive" portfolio, should reflect the true market portfolio. It should not be limited to securities but should reflect all assets that could be held by the overall portfolio. The second benchmark should be a managed futures benchmark as discussed in this chapter.

Table 7 provides the data collected for this example. The risk-free rate was

\footnotetext{
${ }^{5} \mathrm{~A}$ two-year period is not necessarily advocated, but it is convenient and matches the available data.
} 


\section{TABLE 7. Returns to Active Portfolio, Passive Portfolio, Managed Futures, and Managed Futures Benchmark}

\begin{tabular}{|c|c|c|c|c|}
\hline \multicolumn{2}{|c|}{$\begin{array}{l}\text { Wealth at beginning of period: } \\
\text { Percentage committed to managed futures: } \\
\text { Risk-free rate per quarter: }\end{array}$} & \multicolumn{3}{|l|}{$\begin{array}{l}\$ 1,000,000 \\
20 \% \\
1.675 \%\end{array}$} \\
\hline Quarter & $\begin{array}{c}\text { Active } \\
\text { Portfolio }\end{array}$ & $\begin{array}{l}\text { Passive } \\
\text { Portfolio }\end{array}$ & $\begin{array}{l}\text { Managed } \\
\text { Futures }\end{array}$ & $\begin{array}{l}\text { Managed Futures } \\
\text { Benchmark }\end{array}$ \\
\hline March & -0.064 & -0.030 & 0.054 & 0.053 \\
\hline June & 0.062 & 0.063 & 0.001 & 0.281 \\
\hline September & 0.008 & -0.137 & 0.164 & 0.157 \\
\hline December & 0.049 & 0.089 & -0.008 & 0.017 \\
\hline March & 0.081 & 0.145 & -0.016 & 0.012 \\
\hline June & 0.048 & -0.002 & -0.009 & 0.007 \\
\hline September & -0.031 & 0.053 & -0.026 & 0.005 \\
\hline December & -0.067 & 0.083 & 0.094 & 0.140 \\
\hline
\end{tabular}

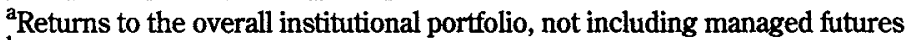

${ }^{b}$ Returns to the portfolio representing a passive benchmark for the institutional portfolio, not including futures-that is, the market portfolio's proxy.

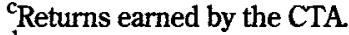

${ }^{\mathrm{d}}$ Returns earned on a benchmark portfolio of CTAs.

1.675 percent a quarter. Although these returns are actual returns, one should not draw any conclusions about performance in general from this simple example.

Part A of Table 8 presents the returns from various combination portfolios. The "Active + Managed Futures" is the actual portfolio that contains an $\mathbf{8 0}$ percent commitment to securities and a 20 percent commitment to managed futures. The other portfolios are various different combinations of active or passive securities strategies and managed or benchmark futures, as described in the table. In addition, for comparison, Table 8 repeats the active and passive returns from Table 7 .

Part B of Table 8 contains the relevant statistical performance measures. The mean quarterly return on the overall portfolio was 1.5 percent, and the standard deviation was 4.2 percent. The Sharpe ratio was 0.254 . The beta was calculated as the covariance of the returns with the passive returns divided by the variance of the passive returns. (Recall that the passive portfolio is the so-called market portfolio.) The alpha is defined as follows:

$$
\begin{aligned}
\alpha= & \text { Mean return }- \text { Expected return } \\
= & \text { Mean return }-[\text { Risk-free rate + (Mean market return } \\
& - \text { Risk-free rate })] .
\end{aligned}
$$




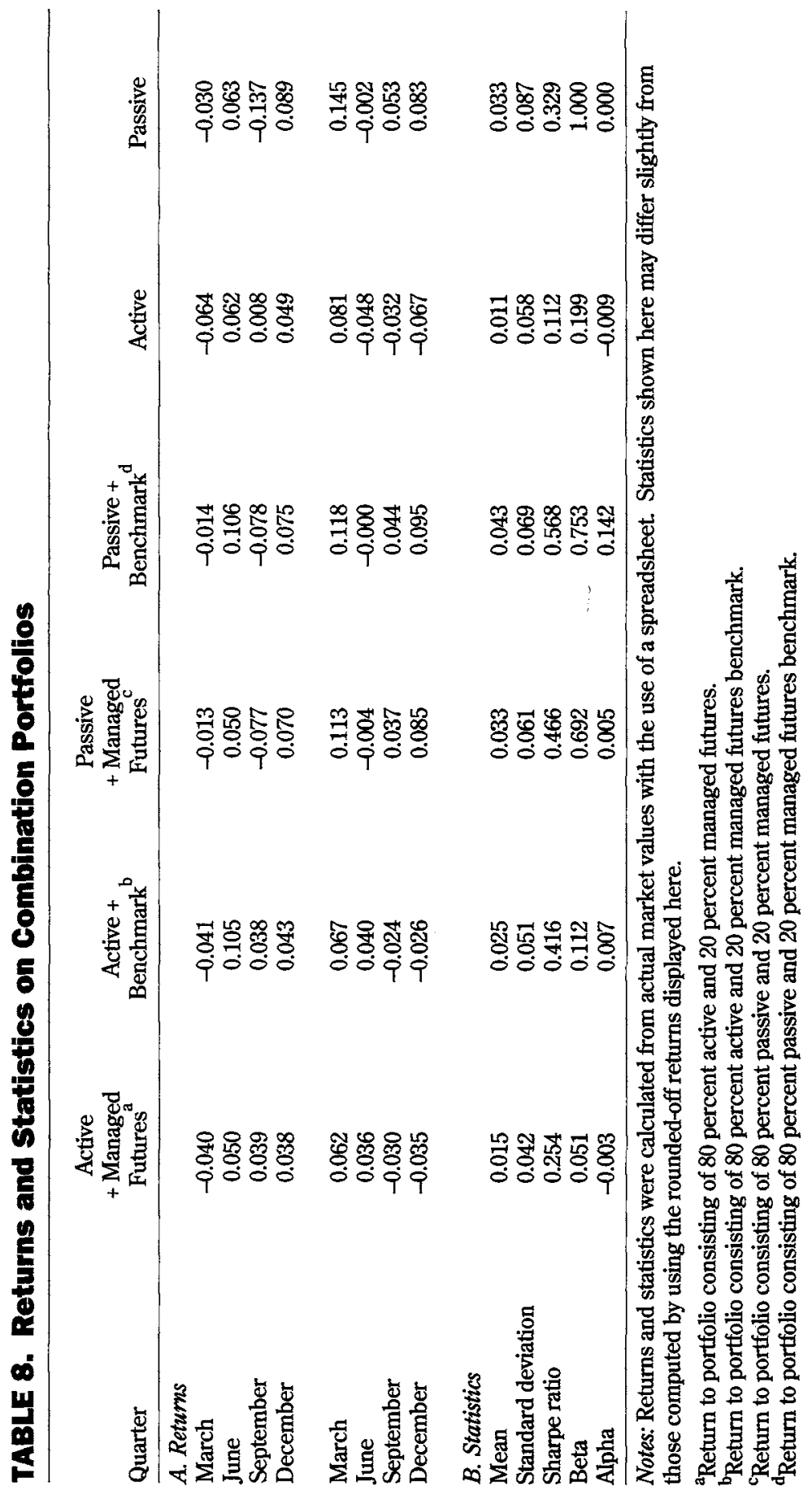


Alpha is interpreted as excess return, which is the return beyond that required to compensate the investor for the risk. Positive (negative) alphas indicate superior (inferior) performance. This performance measure is seldom used in the managed futures industry, but it is used extensively in the securities industry. Alpha lends itself nicely to the approach that will be used here, but other measures can be used with slight adjustments.

The evaluation must also consider the effect of the CTA's performance on other components of the portfolio. Indeed, a CTA might rank extremely high on the Sharpe ratio, even with much consistency over the years, but that same CTA might be totally inappropriate for combining with the active portfolio. In other words, the evaluation must consider the covariance effect with the active part of the portfolio. At the same time, the CTA cannot necessarily be rewarded or penalized simply because his or her performance does not "mesh" well with the active portfolio. The CTA has no control over the active portfolio and probably does not even have access to information about it. The evaluation system presented here deals with these issues.

Table 9 defines the variables to be used in the system and presents the performance analysis of this example. With $A, P, M F$, and $B M$ representing various excess returns, then $A+M F, A+B M, P+M F$ and $P+B M$ represent the returns from the combinations indicated in Table 8.

Now look at the value added in basis points (bps) by including managed futures. The overall portfolio had an alpha of $-26 \mathrm{bps}$, but the active portfolio had an alpha of $-92 \mathrm{bps}$. Thus, the managed futures program added $66 \mathrm{bps}$ of value. Obviously, the active portfolio performed poorly, and the managed futures program reduced this poor performance. The question is: From where did the $66 \mathrm{bps}$ of value come? The answer can be addressed in several ways.

The addition of a 20 percent commitment to managed futures reduced the beta from 0.199 to 0.051 , which automatically reduced the expected return by $24 \mathrm{bps}$. So the risk reduction accounted for $24 \mathrm{bps}$. The remaining $42 \mathrm{bps}$ represent the greater return earned by the CTA than the active manager.

Another way to look at the $66 \mathrm{bps}$ is shown in Part B of Table 9. The alpha from the managed futures benchmark, $B M$, was $160 \mathrm{bps}$. It is computed as the alpha of the portfolio combining the active + managed futures minus the alpha of the active portfolio. Thus, managed futures in general contributed $160 \mathrm{bps}$, and the basic decision to use managed futures was a good one. The CTA's performance, however, was not good. In fact, it cost 94 bps (computed as the alpha from the [active + managed futures portfolio] - the alpha from the [active + benchmark portfolio]). That is, the CTA did not perform well relative to CTAs as a whole. The 66-bp gain from managed futures is the result of 160 bps from the use of managed futures and $-94 \mathrm{bps}$ from the choice of CTA. 


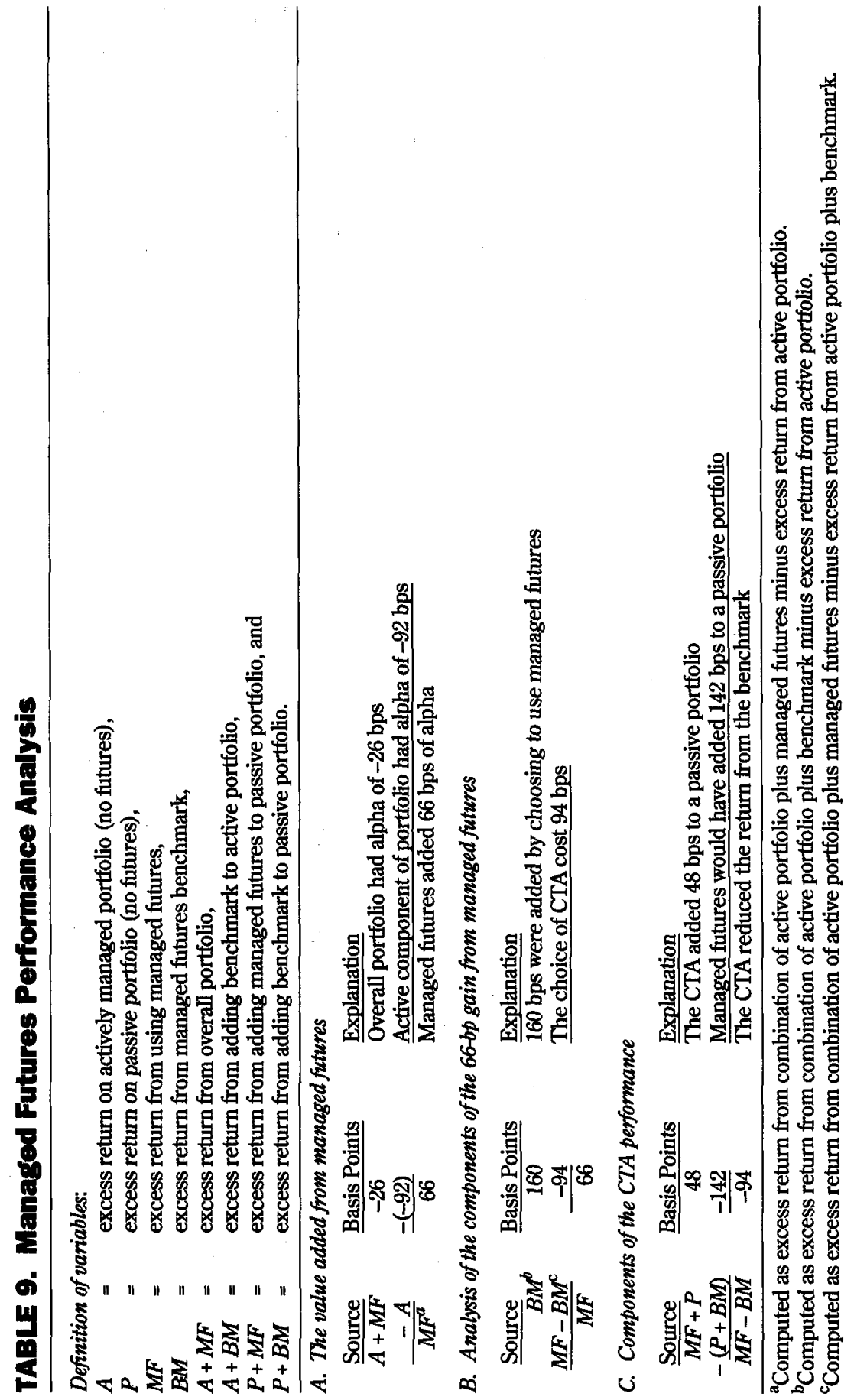


Part $\mathrm{C}$ of Table 9 demonstrates the components of the -94 bps contributed by the CTA. The CTA would have added 48 bps to a passive portfolio; the managed futures benchmark would have added $142 \mathrm{bps}$ to a passive portfolio. (Note that the CTA's performance is expressed relative to the passive portfolio, not the active portfolio. The CTA has no control or even access to the active portfolio and is not responsible for contributing or not contributing to it.) These figures substantiate that the CTA did not perform well.

The overall portfolio manager who makes the decision to use managed futures is responsible for two aspects of the program: the decision to use managed futures, as indicated by the percentage commitment, and the choice of CTA(s). In this example, the decision to use managed futures was correct but the CTA performed poorly. If possible, the managed futures commitment should have been made to a broad group of CTAs representing the benchmark.

As shown in Table 9, alphas are additive; so they are particularly suited to this type of analysis. The Sharpe ratio and other measures are not additive, but they can still be used. For example, the Sharpe ratio for the active portfolio is 0.112 . After adding the futures, the Sharpe ratio increases to 0.254 . The benchmark plus the active portfolio, however, would have produced a Sharpe ratio of 0.416 . Thus, the managed futures benchmark improved the active portfolio's Sharpe ratio, and the decision to use managed futures was a good one. However, the Sharpe ratio was reduced from the 0.416 with the benchmark to 0.254 by the CTA. The Sharpe ratio for the passive portfolio plus the benchmark is 0.568 , and the Sharpe ratio for the passive portfolio plus the CTA is 0.466 . Thus, again, the conclusion is that the CTA did not perform well. ${ }^{6}$

Suppose the managed futures program was multiple CTAs overseen by a manager of managers (MOM). Then, the CTA return should actually reflect the composite returns of all the CTAs, and the MOM is evaluated as if he or she were the CTA. At the administrative level of the overall fund, no evaluation of the individual CTAs is needed; that evaluation is the responsibility of the MOM, who conducts an analysis similar to the one shown in this chapter.

Who is ultimately responsible? The CTA is responsible for his or her own performance relative to the passive portfolio, but the decision to use managed futures and the choice of CTA is controlled at a higher level. If managed

\footnotetext{
${ }^{6}$ Note, however, that no two performance measures, even the Sharpe ratio and the alpha, are guaranteed to lead to the same conclusions.

${ }^{7}$ In this case, the MOM should simply determine the alpha of each portfolio that combined a CTA with the passive portfolio and subtract the alpha from a corresponding portfolio that combined (with the same allocation) the benchmark with the passive portfolio. This process would give the alpha contributed by each CTA.
} 
futures contribute little to the active portfolio over a long period of time, then the program should obviously be terminated. If managed futures contribute but the CTA consistently performs poorly, then the investment manager should look for a new CTA.

Another situation that may arise is that the returns to managed futures or an individual CTA do not combine well with the active portfolio. This type of covariance effect is akin to the results of putting frequent shooters on the same basketball team: The overall team concept may be lost amid the focus on individuality.

This chapter has examined procedures for evaluating the performance of a managed futures program. The simple system that was suggested is reasonably fair; it places strong emphasis on the effects of the managed futures program on the overall portfolio rather than following the traditional approach of evaluating managed futures in isolation. What is most important, however, is that some sort of risk adjustment be performed. Simple rankings of returns are inadequate and misleading. Fortunately, the managed futures industry has been generally responsive to the investor's need for risk as well as return information. 


\section{Legal, Regulatory, Accounting, and Tax Considerations in Managed Futures}

The use of managed futures entails some issues in the legal, regulatory, accounting, and tax areas. This chapter summarizes the issues from a very broad perspective, but the advice of attorneys and accountants is absolutely essential before making a decision to use managed futures.

\section{Legal and Regulatory Aspects ${ }^{1}$}

The futures industry is heavily regulated. The Commodity Futures Trading Commission (CFTC), which was initiated in 1974, is the primary regulatory authority for the futures industry, but certain other regulatory bodies have at least a moderate amount of authority over futures trading. They include the Securities and Exchange Commission (SEC), the U.S. Treasury Department, the U.S. Department of Labor, and relevant state regulatory authorities. Although the industry is covered with regulators and regulations, participants should never assume that their interests are fully protected or even necessarily represented well by government agencies.

For a nonfiduciary investor, regulatory concerns are few. For example, an individual who wishes to invest in a public futures fund or a private pool confronts no real legal constraints. If the fund is publicly offered, it has met the necessary registration requirements. Private pools in the United States are also required to register, but because registration is lengthy and expensive, many private pools are organized as "offshore pools," meaning that they are registered in a foreign country where registration requirements are less costly. In 1992, the CFTC reduced the registration and disclosure requirements for private pools through a regulation known as Rule 4.7. The rule reduced the requirements for certain "sophisticated investors," namely, insti-

\footnotetext{
${ }^{1}$ Much of the material in this section is drawn from Collins and Dygert (1992).
} 
tutions and wealthy individuals. ${ }^{2}$

For investors with fiduciary responsibilities, the use of managed futures must be evaluated with respect to the provisions of the 1974 Employee Retirement Income Security Act (ERISA) and its related rulings. ERISA vests regulatory authority over fiduciaries primarily with the Department of Labor and, to a lesser extent, the Treasury Department and the Pension Benefit Guaranty Corporation. ERISA defines a fiduciary as one who exercises discretionary authority over the assets of a "plan," gives investment advice, or in any way controls the administration of a plan. The definition generally does not include brokers. Whether it includes a particular commodity trading advisor (CTA) or manager of managers (MOM) is important. CTAs and MOMs generally try to structure the arrangement so as to avoid being classified as a fiduciary, and they can do so if certain conditions are met. Even if the CTA or MOM is not classified as a fiduciary, however, it will still be allowed control over futures margin accounts, which are not considered plan assets.

ERISA and subsequent Department of Labor rulings dictate that the fiduciary manage the plan assets as a "prudent person" would, which is generally interpreted to mean that relatively conservative policies should be followed and that diversification is encouraged, if not required. Moreover, the extent to which the fiduciary complies with the law is evaluated with respect to the entire portfolio. This requirement generally means that managed futures programs, potentially quite risky if viewed in isolation, can be considered reasonable, if not sensible, additions to an overall portfolio, particularly in light of their demonstrated diversification benefits. A strict interpretation of the law might even someday mean that failure to diversify fully could subject the fiduciary to liability if losses were exacerbated as a demonstrated result of the failure to use managed futures. ${ }^{3}$

Anyone who controls the investment of plan assets is required to be registered with the SEC as an investment advisor under the 1940 Investment Advisers Act. Thus, CTAs and MOMs, who are already registered with the CFTC, are also required to register with the SEC.

A number of regulations affect payments made to CTAs and MOMs and

${ }^{2}$ The SEC has had a rule of this sort in place for many years for pools that invest in securities and instruments regulated by the SEC.

${ }^{3}$ Although such an interpretation has not yet been given, a similar ruling did appear in 1992. The Indiana Court of Appeals upheld a lower court ruling that the directors of a grain cooperative were liable for losses that could have been reduced by hedging. The directors had previously been shown the benefits of hedging and had actually implemented a small hedging program, but they were nevertheless found liable. See Brane v. Roth, 590 N.E.2d 857 (Ind.App. 1 Dist. 1992). 
apply to potential conflicts of interest, such as their directing trades to firms in which they have a financial interest. Incentive fees are also closely regulated. The 1940 Act generally prohibits incentive fees because of the potential conflicts they create, but SEC Rule 205-3, enacted in 1985, creates certain exemptions to the 1940 Act. The Department of Labor has modified these rules to make them apply to incentive arrangements for pension plans. For example, the fee must be solely related to growth in the value of the account, either party can terminate the arrangement with 30 days notice, the details must be disclosed and agreed upon, the amount paid must be reasonable, and the client must have at least $\$ 500,000$ under management with the advisor or a net worth of at least $\$ 1$ million. Several other conditions must also be met.

Finally, some state laws address the use of managed futures. Although regulators are likely to develop a more relaxed view in time, the use of managed futures by fiduciaries continues to experience problems in the political arena. The Virginia Retirement System, which introduced a managed futures program in 1991, successfully fought a bill proposed in the state legislature in 1992 to ban the use of futures transactions.

\section{Accounting and Tax Aspects}

With some exceptions, accounting for futures contracts is done on a markto-market basis. When a futures contract is created, no accounting entry is made. As gains and losses are realized through the daily marking to market of contracts by the clearinghouse, the gains and losses are recognized immediately as income. ${ }^{4}$ Foreign-currency futures, which would appear to fall under the special rules for accounting for foreign-currency transactions, are in this case treated just as any other futures contract. Options, however, are actually assets and liabilities, and the premiums are recorded as such. Although this treatment makes the accounting issues seem simple, the specific rules and procedures are complex and change from time to time.

The taxation of futures contracts has become an important issue in recent years. Any tax advantages of futures trading have been largely closed; indeed, in some cases (the area of hedging, in particular), futures have occasionally been the subject of unfavorable and unclear tax rulings.

For nontaxable investors, the most important relevant issue is the Unrelated Business Taxable Income rule. It provides that certain leveraged transactions by nontaxable investors can generate taxable income. An Internal Revenue

\footnotetext{
${ }^{4}$ For details, see Financial Accounting Standards Board Statement of Financial Accounting Standards No. 80, "Accounting for Futures Contracts," the authoritative source for firms following generally accepted accounting principles.
} 
Service ruling appears to exempt income from futures trading from this rule, but expert legal and tax advice would be necessary to clarify this point before starting a managed futures program.

For taxable investors, the rules regarding futures trading stipulate that all realized and unrealized gains are taxable. Thus, all open contracts at year end are marked to market, as usual, and all accumulated gains are taxable. Gains and losses are treated as 60 percent long term and 40 percent short term. Long-term losses are subject to certain limitations.

Because of the complexity of legal, regulatory, accounting, and tax issues, this chapter could do no more than expose the reader to the relevant concerns that should be addressed when considering a managed futures program. This monograph does not attempt to render legal, regulatory, accounting, or tax advice, and no statements made in it should be interpreted as such. Clearly, the assistance of attorneys and accountants is critical to assure that all regulations and procedures are followed. 


\section{Setting Up a Managed Futures Program}

Any individual investor may contract with a commodity trading advisor (CTA) or commodity pool operator (CPO) for a managed futures program through a public fund or private pool. The focus of this chapter, however, is the managed futures program for institutional investors.

The process has three main components: research, system design, and selling the program to trustees. Throughout this chapter, the individual responsible for the portfolio is called "the administrator" to distinguish that person from the trustees who make the ultimate decision to go ahead or not go ahead with the program. The trustees may be actual trustees of a pension plan or a subcommittee representing the board of directors with responsibility for a pension plan.

The format suggested in this chapter is not necessarily the only one that could be followed. It is offered simply as a reasonable structure for a program's development.

At any point in the process, the designers may decide that a consultant is necessary. The stage at which the consultant enters will depend on the technical expertise of the administrator and his or her staff. The consultant should be independent-that is, have no vested interest in what decision is made about implementing a managed futures program.

\section{Research}

The reader of this monograph should not in any way be convinced that a managed futures program is appropriate for all institutional investors. A considerable amount of background research must be done to determine whether managed futures are appropriate for adding to a specific portfolio. The research should provide the input necessary to convince the administrator to propose formally to the trustees that the program be established. Obviously, the trustees must be convinced, and this task will also take a considerable amount of research.

First, the administrator should determine if the program can legitimately 
be established. Do any laws or corporate policies restrict the portfolio's involvement in futures trading? If restrictions exist, extensive legal work may be needed to permit the program to operate.

The administrator should start the economic analysis by carefully examining the literature on the performance of managed futures. This monograph summarizes the literature, but the administrator should read many of the articles. ${ }^{1}$ The research findings apply only to the use of managed futures in general. The administrator should investigate whether managed futures will be a valuable addition to the administrator's particular portfolio.

This step involves determining how the portfolio would have performed had it included managed futures. This analysis requires not only data but also technical expertise. The administrator will need information on the portfolio's historical rates of return for at least five years. The returns should be "total returns"-that is, including all dividends and interest. Most importantly, the returns should be time weighted rather than dollar weighted.

Time-weighted returns for a representative managed futures series for the same period are also needed. Appendix A contains information about several futures return series. The two unmanaged series, the Goldman Sachs Commodity Index and the Commodity Research Bureau Index, would probably not be appropriate because they represent the returns from passive futures trading. The other series are those of active futures managers, and the data can be obtained from the consulting firms that specialize in managed futures. Keep in mind that these indexes are indicative of the performance of a portfolio of managed futures traders. They do not represent a typical trader. Because the volatility of an index of managed futures traders will be less than the volatility of an individual trader, the index could overstate the risk reduction to be expected from using a single trader or only a few traders. As discussed later in this chapter, after the CTAs have been chosen, additional studies should be done on the actual risk reduction that could have been obtained had the selected CTAs been used in the past.

To carry out the study of potential past performance, the administrator must make a preliminary decision on the amount of funds to allocate to managed futures. Most first-time users start with a small percentage, with the objective of increasing that amount later. A reasonable starting size is 1 percent of the portfolio. A commitment of this amount is likely to have little effect on the overall risk-return profile of the portfolio but might provide acceptable econo-

\footnotetext{
${ }^{1}$ The administrator could hire a consultant to read and summarize the technical articles and present the data in a report or group of abstracts.
} 
mies. On the other hand, a more cost-effective program might be attained with only a slightly larger allocation.

This initial study should provide the average return, standard deviation, and if of interest to the administrator, the maximum drawdown, maximum return, minimum return, and any other relevant statistics. The time period, as noted, should be at least five years but longer if possible and, perhaps, should be broken down into subperiods. Although portfolio managers will not necessarily form efficient portfolios, deriving the efficient set with and without the futures returns is important because this information is the best indicator of improvements in the risk-return trade-off. If the results of this study indicate significant improvement in the risk-return profile of the portfolio, the administrator should proceed to design the system.

\section{System Design}

At this stage, the administrator does not necessarily have to be convinced that the firm should use managed futures. He or she need only be convinced to proceed with the design of a system. If, because of cost or some other reason, such a system cannot be constructed, then the administrator should terminate the project.

The administrator should begin by formulating some objectives for a managed futures program; for example, the objective may be to add 200 basis points in return with a 10 percent reduction in risk. Of course, the objectives need to be realistic and formulated in light of the results found from the historical studies that used the managed futures index data. The objectives should also, however, set a fairly high standard that challenges the CTAs who will later be chosen. If the objectives prove to be unrealistic, they can be revised.

At this point, the administrator will need to determine the approximate number of CTAs to use. Because of futures' diversification potential, the trend is toward the use of multiple CTAs, which will probably require the use of a $\mathrm{CPO}$ or manager of managers (MOM). The administrator should send out requests for proposals from MOMs and CTAs.

Of course, many CTAs may be interested, so some culling will soon be necessary. The administrator should investigate the applicants' backgrounds and check with the Commodity Futures Trading Commission, the National Futures Association, and the Securities and Exchange Commission to determine that these individuals are properly registered and to discover the existence of any past or outstanding complaints against them.

The administrator should then request performance data that can be inte- 
grated with the portfolio's returns. ${ }^{2}$ Studies should then be done that are similar to those described earlier. The administrator should look at the proposed CTAs individually and as a group. Of course, historical data are not necessarily representative of future performance, even with regard to diversification potential, so subperiod analyses should be conducted. The administrator should look carefully at the CTAs' trading histories-if possible, by size of account because this factor can affect a CTA's trading style. The studies should also look at the risk of the system, not only in terms of standard deviation or drawdown, but also with respect to risk of ruin. In other words, it is possible to compute the probability that the traders will trade in such a manner that their returns will lever the portfolio and combine with a sharp market movement so as to endanger the stability of the portfolio. Although no specific guidelines on an acceptable probability of ruin are possible, such an occurrence, for all practical purposes, should never be expected. In addition at this point, the administrator will have to make a fairly firm decision on the percentage of the portfolio to allocate to managed futures. Although this percentage can always be changed, it can have a significant impact on the design and cost of the system.

At this point, the administrator should again cull the list of potential CTAs so that the remaining ones are those most likely to be chosen. The next stage is to design the operating system. Either the CTA or the MOM must develop a set of well-documented procedures that cover the program's daily trading operations, accounting, cash management, risk control, reporting, and auditing. Risk control is of special importance. Either the administrator or the MOM must be well aware at all times of the risk of the system and have the power to reduce that risk rapidly and effectively. Risk may increase, for example, when a large group of CTAs trade the same market at the same time and take the same side of the market. Thus, the administrator or MOM must be able to force the CTAs to change their positions quickly or execute an offsetting hedge transaction.

An effective back-office system is critical to the smooth functioning of the program. The administrator may want to design the firm's own back-office management for the futures program, but it is likely to be expensive. Many MOMs specialize in providing full back-office support, or if the firm is not using a MOM, a consulting firm can provide back-office services.

A custodial relationship will also be necessary. The custodian operates in the interest of the firm and provides administrative services and financial

\footnotetext{
${ }^{2}$ It is assumed that the number of potential candidates has been pared down at this point to a reasonable number on which to do further studies.
} 
controls that assure correct operation of the system.

Once the system is designed, the question of fees must be addressed. The managed futures industry has no standard fee structure, and fees are flexible. The administrator can and should negotiate directly with the MOM or individual CTAs to obtain the most attractive fee structure. Remember that the fee structure includes not only operating costs but administrative fees, commissions, and incentive fees. Some structures are multilayered and thus have some duplication of costs. ${ }^{3}$ The layering is not necessarily bad, but it should be carefully evaluated with respect to benefits relative to costs.

Commissions should be negotiated down to about $\$ 10$ per contract or less. Keep in mind that the commission brokers, called futures commission merchants, may be affiliated with the MOM or certain CTAs. Although they may offer the lowest contract rates, they may also have a conflict of interest that could lead to excessive trading.

Recall from Chapter 3 that incentive fees that pay each CTA based on performance may result in the payment of incentive fees even though the overall portfolio has lost money. In order to determine an appropriate incentive fee structure, the administrator must decide on a fair method of evaluation (refer to Chapter 5). If desired, the administrator can negotiate these arrangements in such a way that incentive fees are not paid unless all costs are covered or if there is an accumulated loss by the CTA.

The final element the administrator must develop is a performance evaluation system for the program (refer to Chapter 5). Criteria should be identified that will determine whether the program has been a success or not, and regular reviews and audits of the program should be conducted. If an MOM is used, he or she should evaluate the individual CTAs and be prepared quickly to replace any if necessary.

At this point, the administrator must decide whether an effective and economical system is possible. Although considerable time and money will have been spent, the administrator should not be reluctant to recommend against the program if that recommendation is appropriate. Assuming, however, that a decision to go forward is made, the next step is critical: convincing the trustees.

\section{Selling the Program}

To convince the trustees, the administrator will probably need to write a

\footnotetext{
${ }^{3}$ For example, an MOM may control the program through supervision of several trading firms that, in turn, employ independent traders. The independent traders may work for more than one trading firm; thus, an individual CTA could trade more than one account for the program. In some systems, the CTA is unaware of whose funds he or she is trading.
} 
report and make one or more oral presentations. Unfortunately, because of long-standing suspicions about the futures markets on the part of some individuals (primarily, those who are not familiar with the markets), considerable resistance can be expected from one or more trustees. These individuals will need to be convinced by demonstrating managed futures' economic benefits and the risk controls and (presumably) reasonable costs the administrator has designed into the program.

One useful selling point may be to show how the risk of the proposed program compares with the risk of the portfolio already in place. In other cases, the portfolio may have already been using futures for asset allocation, cash management, or hedging, and this circumstance can facilitate the administrator's selling task. In addition, the administrator can elicit the services of an outside, disinterested party to help convince the trustees.

After the trustees approve the program, a final problem then often arises. If the portfolio is a pension fund of a large corporation, employees and retirees will hear about the decision to use futures and may assume that the fund is gambling with their retirement money. Much unwanted negative publicity may appear. ${ }^{4}$ The administrator and trustees will now have to spend considerable time fighting a public relations battle.

The most damaging publicity generally comes from an outside, often uninformed, source. Therefore, administrators and trustees should be prepared to preempt the negative publicity by disseminating positive, accurate publicity as soon as the program is approved, or sooner if possible.

The growing acceptance of managed futures programs indicates that many firms have found ways to overcome the inherent tendency of the uninformed to be skeptical of futures.

\footnotetext{
${ }^{4}$ For example, when the Virginia Retirement System decided to begin a managed futures program, the story was broken by the Wall Street Journal (see Angrist 1991). It was followed by a host of negative and controversial articles in media throughout Virginia, which culminated in an article in the December 1991 issue of Virginia Business, the cover of which pictured individuals standing on the edge of a crevice while throwing dice.
} 


\section{Summary}

Until the creation of financial futures, the securities and futures industries operated like two trains running along parallel tracks. The securities industry often distrusted the futures industry, and its suspicions were not alleviated by the geographical separation of the two markets, with the former located primarily in New York and the latter situated almost exclusively in Chicago. The futures industry, composed largely of individuals and small firms, viewed the securities industry as a lackluster, boring arena controlled by institutional investors. Trading in the futures pits, in contrast, depended on individual initiative and entrepreneurship.

With the advent of financial futures, however, price relationships between securities and futures were formally linked. That the two industries needed each other soon became apparent, and they began to merge into a single, unified, and efficient market for investment and risk management. Stock index futures, introduced in 1982, although associated with some controversy, were probably the single most important innovation in this process.

Specialized professional investment managers developed in a parallel manner in both industries and, someday soon, will begin to recognize the mutual benefits of working together. The securities industry, whose fundamental operatives are the financial analysts and portfolio managers, has shown a growing desire to learn about the investment opportunities offered by derivatives. The cause is partly the increasing technical education of its participants and ultimate users - in particular, the pension funds, mutual funds, and banks. Investment managers can no longer look at stocks and bonds in isolation from other markets. Derivatives provide opportunities to enhance portfolio return and reduce risk, not only through their use in asset allocation, cash management, and hedging strategies, but also, ultimately, by integrating them fully into a portfolio through a managed futures program.

The increasing acceptance of managed futures as a distinct asset class has led to rapid growth of the managed futures industry. Although the growth in public funds and private pools has been stunted by their continuing reputation of extreme costliness, private contractual arrangements between institutional investors and commodity trading advisors offer many benefits and reasonable 
costs.

The securities industry is slowly recognizing the opportunities in futures trading and realizing that, working together, these two industries can enhance the value of their clients' investments. Their clients, increasingly sophisticated themselves, are demanding that enhanced value. 


\section{Appendix A. Measures of Passive and Managed Futures Performance}

Performance measures can be generally divided into those applicable to passive futures trading and those applicable to active futures trading.

\section{Passive Futures Performance}

Passive futures trading is the buying and holding of futures contracts. Two primary indexes can be used to reflect the performance of a passive futurestrading strategy.

The Goldman Sachs Commodity Index (GSCI) was created by Goldman, Sachs \& Company in conjunction with the Chicago Mercantile Exchange, which began offering trading in futures and options on futures on the GSCI on July 28, 1992. The GSCI futures contract is based on an index of futures contracts. ${ }^{1}$

Although trading volume has been light, the GSCI is an excellent reflection of a passive futures-trading strategy. Each commodity on which there is a futures contract that is included in the index is weighted according to world production of the physical commodity. To be eligible for inclusion, a commodity must have had at least 750,000 contracts traded on a futures exchange during the previous year. The futures exchange need not be in the United States; the GSCI includes futures from the London Metal Exchange as well as several U.S. exchanges. A futures contract's trade-weighted volume (futures volume multiplied by contract size) must be at least 33 percent of the five-year world physical production. The index is based on the nearby futures contract price.

The GSCI consists of futures on aluminum, cocoa, coffee, copper, corn,

\footnotetext{
${ }^{1}$ This type of futures contract is unusual but not unique, nor was this one the first such contract. Afutures contract trading on the Commodity Research Bureau Index (discussed next) began earlier than the GSCI contract.
} 
cotton, crude oil, gold, heating oil, live cattle, live hogs, platinum, silver, soybeans, sugar, unleaded gasoline, wheat, and zinc. Note that no financial or currency futures are included. Because of its large volume of world production, the index is heavily weighted toward the oil contracts, which has been its major criticism.

Figure A.1 shows the GSCI for 1970 through 1992 . Note the spike in the GSCI in 1991, a result of the sharp increases in oil prices surrounding and during the Gulf War. Sharp oil price increases also occurred in.1974.

\section{FIGURE A1. Goldman Sachs Commodity Index}

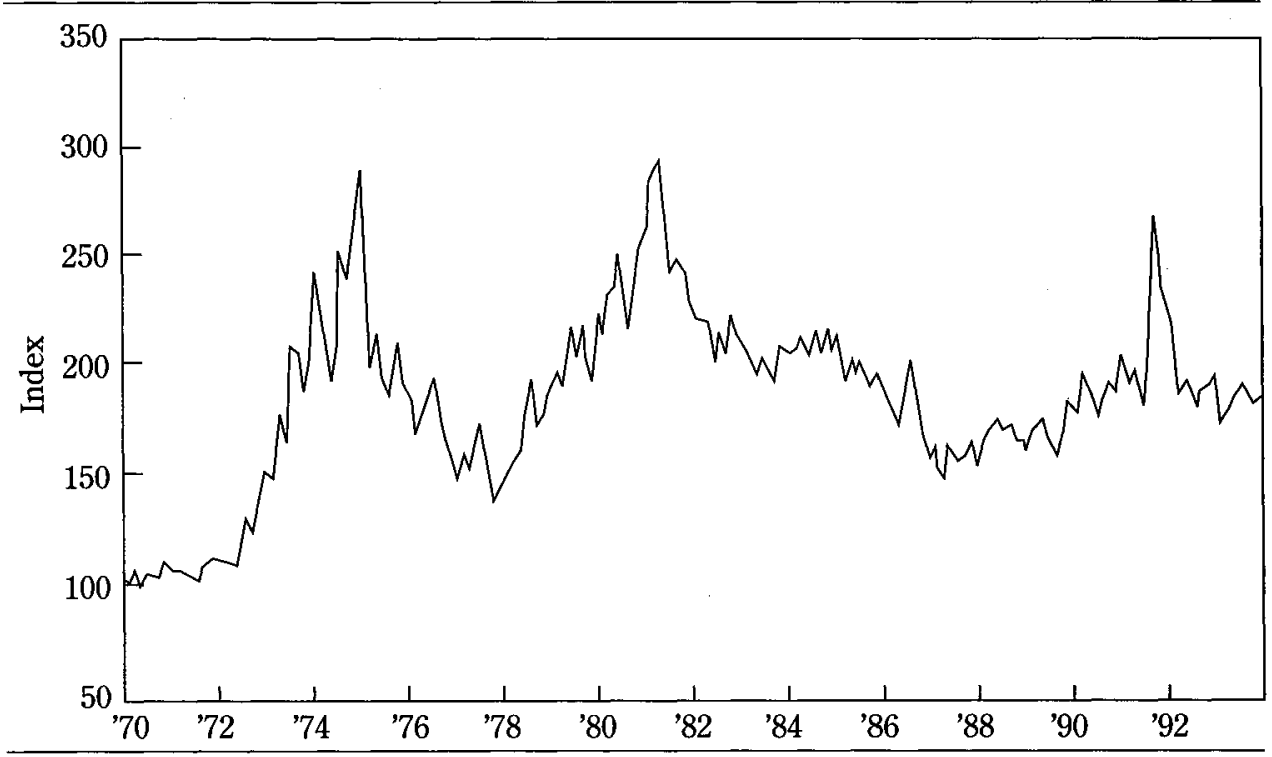

Source: Chicago Mercantile Exchange.

The Commodity Research Bureau (CRB) Index is based on the prices of several contract months for 21 commodities, which are equally weighted. The New York Futures Exchange began trading futures on the CRB Index in 1986, but volume has been low.

Figure A.2 contains the history of the CRB Index for 1970 through 1992. The CRB Index and GSCI have many similarities but also many differences. The correlation between percentage changes in the two indexes is 0.75 , which is highly positive but not as strong as the correlation between most stock index returns. Note that neither the 1974 nor the 1991 spikes characteristic of the GSCI (Figure A.1) appear in the CRB Index.

Whether the heavy weighting of oil in a commodity index is good or bad is 


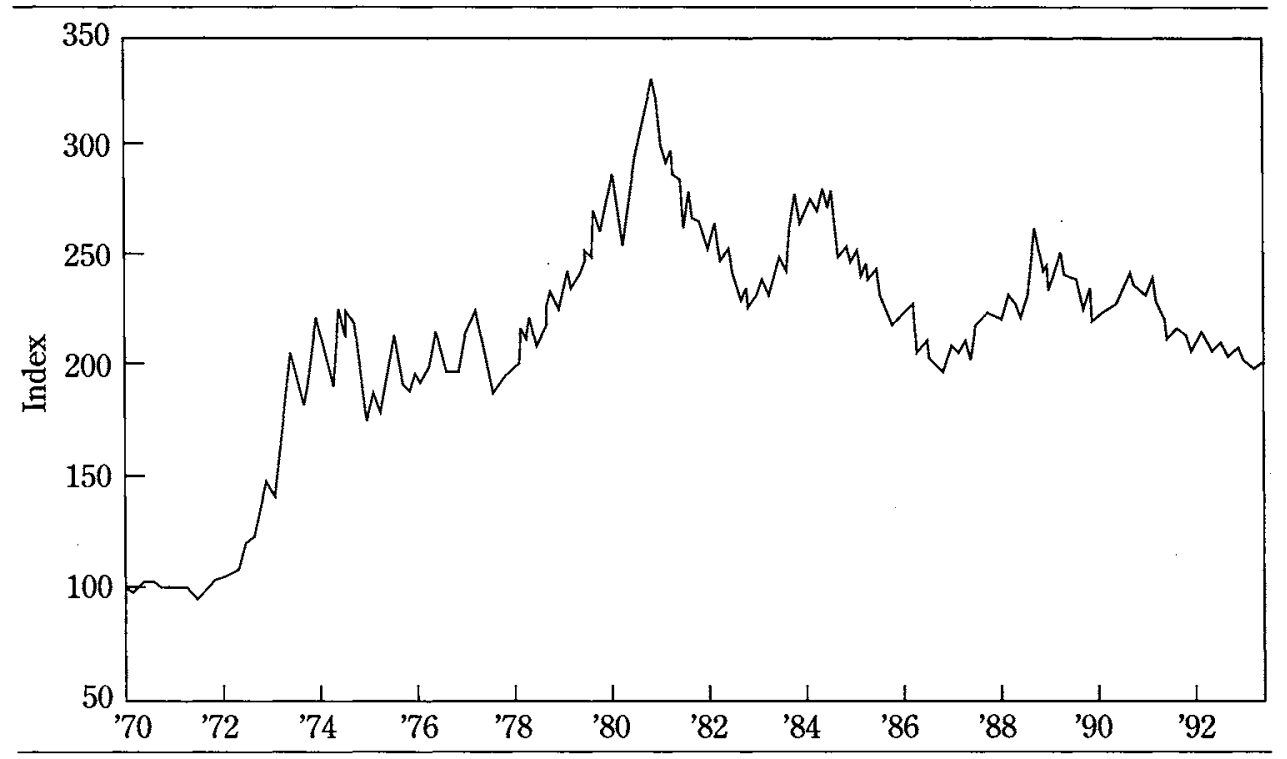

Source: Chicago Mercantile Exchange.

debatable. Oil is certainly a major commodity, and its impact on the GSCI is proportional to world production, but whether its influence in the index is proportional to its influence on consumer goods is not clear. Neither index, however, is specifically designed to be a measure of commodities in general in proportion to their use in everyday life.

\section{Managed Futures Trading}

The primary indexes for managed futures trading were mentioned throughout this monograph and are described in this section.

The Barclay Indexes. The Barclay Trading Group, Ltd., is a consulting firm that specializes in managed futures. Founded in 1985, Barclay provides a variety of consulting services and publishes the Barclay Managed Futures Report and the Barclay Institutional Report.

Barclay maintains two indexes of managed futures activity of commodity trading advisors, the Barclay CTA Index and the Barclay CTADollar-Weighted Index. Both indexes are constructed from a data base that tracks the monthly performance of more than 350 futures and derivative money managers worldwide. The CTA Index is an equally weighted average of the monthly returns of a number of managers. In 1992, the index included 197 managers. The CTA 
Dollar-Weighted Index is constructed by weighting the returns of each manager by the funds under management. To be included in the index, the CTA must have four years of prior performance history, but to remove any distortions caused by possible abnormal performance at the onset, the index ignores the first four years of performance history.

Barclay also provides seven subindexes. Five are based on the compositions of the portfolios of the traders. For example, the Agricultural Traders Index is an equally weighted average of managed programs that specialize in agricultural futures. In 1993, there were 16 such programs. Other similar indexes are the Currency Traders Index (44 programs), the Diversified Traders Index (152 programs), the Energy Traders Index (21 programs), and the Financials and Metals Traders Index (86 programs).

Barclay also produces two subindexes based on trader styles. The Discretionary Traders Index is an equally weighted index of discretionary (that is, judgmental) programs that in 1993 covered 80 such programs. The Systematic Traders Index is an equally weighted index of programs that are based at least 95 percent on the use of systematic procedures (formulas, technical rules, and so on).

Barclay reports its index figure as a return. Figure A.3 shows the Barclay CTA Index (unweighted) from 1980 through $1992 .{ }^{2}$ The Barclay CTA Index (which starts in 1980) is noticeably different from the GSCI. The Barclay Index's upward trend apparently reflects the management skills of the CTAs included in it; the GSCI simply reflects the returns from a buy-and-hold strategy. Although the upward trend reflects well on the performance of the CTAs, remember that it does not prove that the performance was especially outstanding.

The Managed Accounts Reports Indexes. Managed Accounts Reports, Inc. (MAR), one of the leading firms monitoring the managed futures industry, publishes Managed Accounts Reports. MAR provides two indexes weighted by the dollars under management. The MAR indexes include historical data not only of current traders but also of traders who have stopped trading because of poor performance, death, or other reasons. The indexes are based on returns net of expenses.

The MAR Trading Advisor Qualified Universe Index includes all trading advisors who have at least $\$ 500,000$ under management and who have traded for at least one year, or who trade for a public fund tracked by MAR. In 1993,

\footnotetext{
${ }^{2}$ The Barclay Index was constructed here from monthly return data provided by the Barclay Trading Group. The index was arbitrarily set at 100 on December 30, 1979.
} 


\section{FIGURE A3. Barclay Unweighted CTA Index}

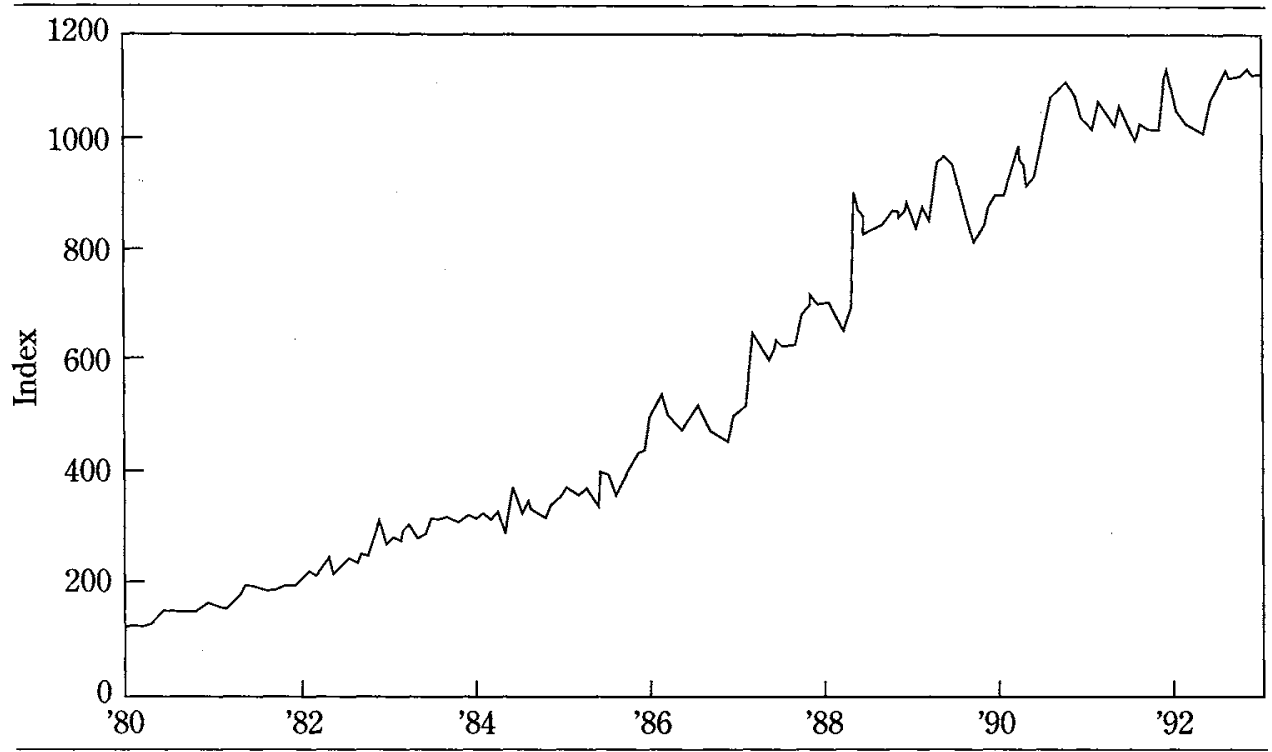

Source: The Barclay Trading Group.

this group included traders who managed about $\$ 14$ billion. Approximately 43.7 percent were trend followers, 20.2 percent were technical analysts but not trend followers, 26.7 percent were discretionary, 2.9 percent specialized in arbitrage trading, and the remaining 6.5 percent did not indicate their styles. Of these traders, 52.6 percent traded diversified programs, 15.2 percent specialized in currencies, 19.1 percent concentrated in financials, 6.9 percent specialized in energy products, and 6.2 percent focused on various other contract groups. The indexes are weighted by the dollars under management. ${ }^{3}$ Figure A. 4 presents the Trading Advisor Qualified Universe Index from 1980 through 1992. Like the Barclay Index, it trends upward during the period.

MARalso publishes an index of funds, referred to as its Fund/Pool Qualified Universe Index. The index applies no minimum size requirements for a fund to be included, and in 1993, it contained 419 funds and pools accounting for a total of $\$ 4.62$ billion. Figure A.5 presents the MAR Fund/Pool Qualified Universe Index history for the 1980-92 period.

MAR also generates a number of subindexes. From the Trading Advisor data, it produces a Discretionary Advisors Index, a European Advisors Index,

\footnotetext{
${ }^{3}$ MAR also provides equally weighted versions of all its indexes, but these versions are not widely publicized.
} 
FIGURE A4. MAR Trading Advisor Qualified Universe Index

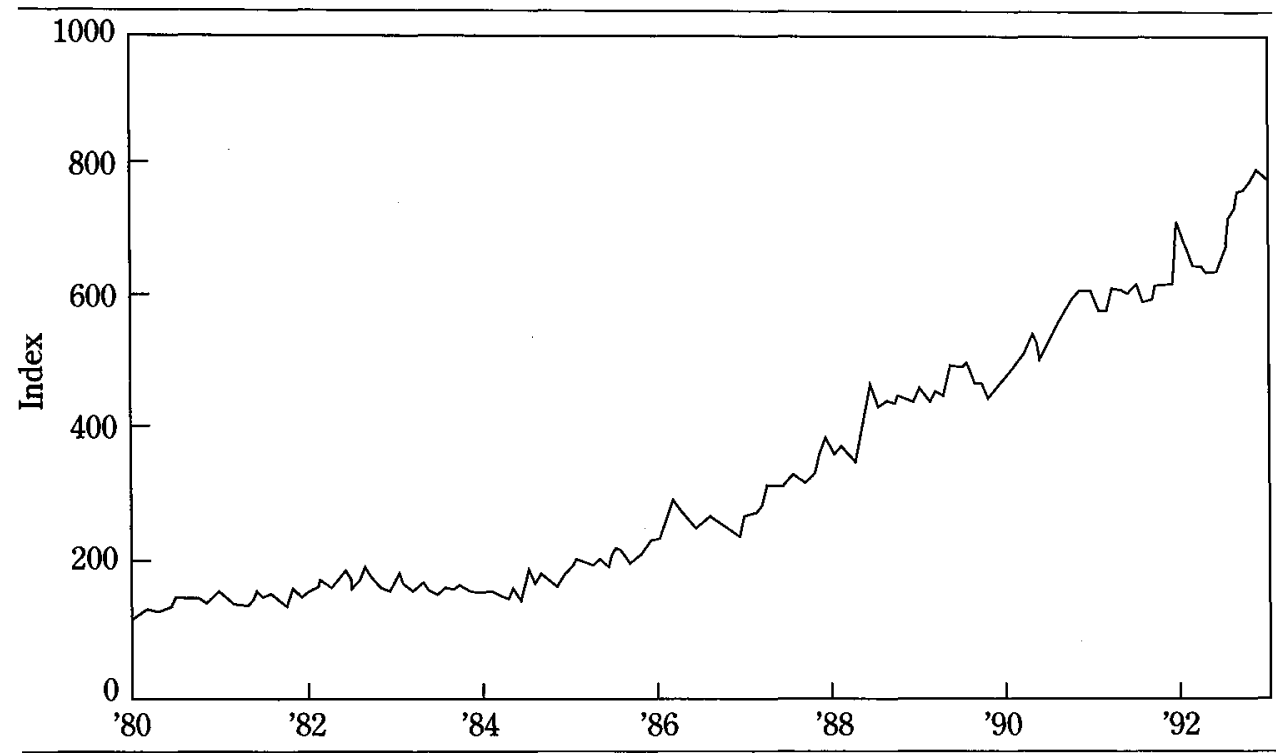

Source: Managed Accounts Reports.

\section{FIGURE A5. MAR Fund/Pool Qualified Universe Index}

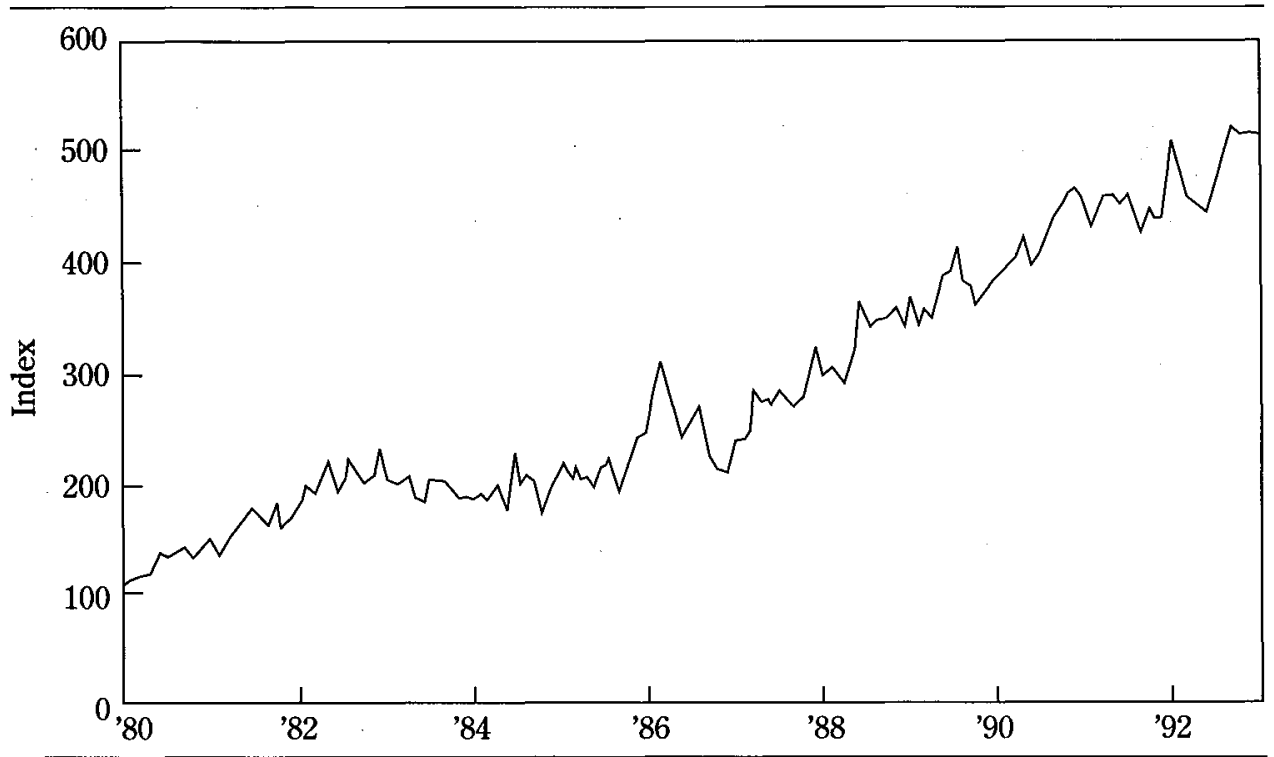

Source: Managed Accounts Reports. 
a Trend-Followers Index, a Currency Programs Index, a Diversified Programs Index, an Energy Programs Index, and a Financial Programs Index. From its Fund/Pool data, it produces a Public Funds Index, a Private Pools Index, an Offshore Funds Index, a Guaranteed Funds Index, a Single Advisor Funds Index, and a Multiple Advisor Funds Index.

The Mount Lucas Management Index. Mount Lucas Management Corporation is an advisory firm in the managed futures industry. Its Mount Lucas Management Index (MLMI) attempts to simulate the trading returns of a simple trend follower. The index started in 1961, when it included 12, primarily agricultural, futures markets. It currently consists of 31 markets spanning the entire spectrum of futures contracts except the S\&P 500 Index futures.

Recently, Mount Lucas entered into an agreement with BARRA to promote and create a means by which an investor can actually purchase the index, automatically receiving the return on the index. The index will be called the MLMI/BARRA Index.

The index is based on daily closing prices of the nearby contract month. Each December, Mount Lucas determines which commodities it will include in the index for the next year. If the commodity is traded on more than one

\section{FIGURE A6. The MLMI}

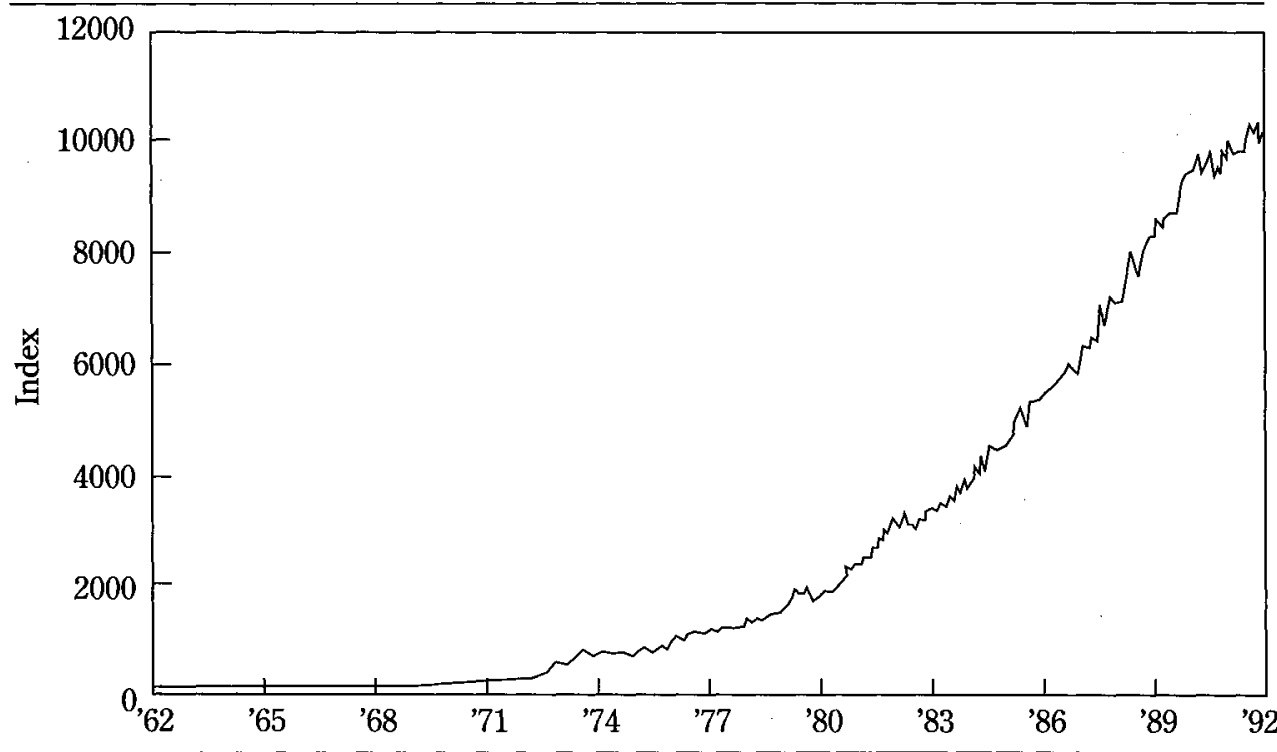

Source: Mount Lucas Management. 
futures exchange, Mount Lucas uses the prices only from the most active exchange.

Because the index tries to simulate an active trading strategy, it can take long and short positions. In a given month, the position is long if the market's closing value of the prior month is above the market's 12-month moving average of closing prices; otherwise, the position is short. "Value" is defined in terms of a unit asset value based on a $\$ 1$ initial investment in a fully collateralized position. In other words, if one invested $\$ 1$, and the next month, the futures price increased 5 percent, then the unit asset value would be 1.05 .

Mount Lucas then reports its index in terms of a monthly rate of return. If the position is long, the return is simply the percentage change in the index. If the position is short, the return is -1 times the percentage change. The monthly returns for all included contracts are pooled into a simple unweighted average to obtain the overall index return. The overall index is then defined relative to a base of 1000 in January 1961. Each month's value is the previous month's value multiplied by the product of 1 plus the monthly rate of return.

Figure A.6 presents the MLMI for 1961 through 1992. Note that it is similar to the other unmanaged indexes in trending upward, and the previous caution about interpreting the index returns as abnormal applies. 


\section{Appendix B. Sources of \\ Information on \\ Managed Futures}

In addition to the bibliography in this monograph, sources of information about managed futures include numerous firms and several associations and regu-

lators. Among the best known are the following:

\section{Trade Associations}

- Managed Futures Association

P.O. Box 287, Palo Alto, California 94302

415-325-4533

(refer to Chapter 2)

- Futures Industry Association

2001 Pennsylvania Ave., N.W., Suite 600, Washington, D.C. 20006 202-466-5460

(a professional organization representing futures commission merchants and serving as a forum for adjudicating disputes)

- National Futures Association (NFA)

120 Broadway, Suite 1125, New York, New York 10271

212-608-8660

(a nongovernmental self-regulatory organization for the futures industry also serving as a forum for adjudicating disputes; most individuals offering futures-related services to the public are required to be registered with the NFA)

\section{Regulatory Agencies}

- Securities and Exchange Commission 450 Fifth St., N.W., Washington, D.C. 20549 202-272-3100

(the regulatory authority for securities markets; responsible under the 1940 Investment Advisers Act for the registration of all investment 
advisors offering services to the public, including, therefore, most commodity trading advisors)

- Commodity Futures Trading Commission 2033 K St., N.W., Washington, D.C. 20581 202-254-6387

(the regulatory authority for the futures industry)

\section{Private Firms}

- Managed Accounts Reports 220 Fifth Avenue, 19th Floor, New York, New York 10001-7781 212-213-6202

(produces a monthly 32-page newsletter, Managed Accounts Reports, containing industry news, reviews of commodity trading advisors, fund and pool rankings, and various other analyses; produces a quarterly performance report in the form of a 400-page book providing more than 40 performance indicators for each advisor that it tracks; sponsors regular conferences in the United States, Europe, and Asia; working on a directory containing reviews of all CTAs back to 1979; see Appendix A for indexes)

- Barclay Trading Group, Ltd. 508 N. 2nd Street, Suite 304, Fairfield, Iowa 515-472-3456 (in Iowa), 800-338-2827 (outside Iowa) (publishes the Barclay Managed Futures Report, a quarterly newsletter containing performance rankings, roundtable interviews, general articles on managed futures, and research reports, and the quarterly Barclay Institutional Report, which contains performance analysis data on the money managers maintained in Barclay's data base of commodity trading advisors)

- Stark Research, Inc.

P.O. Box 591, Palatine, Illinois 60078

708-359-4508

(publishes the monthly newsletter Norwood Index Report, which contains articles, performance statistics, and reports on various trading firms) 
- California Managed Accounts (CMA)

T. Young \& Company, Inc., 236 White Oak Way, Santa Ynez, California 93460

805-686-3004

(produces the monthly CMA Reports, which provides rankings for more than 60 CTAs, reviews of certain CTAs, and consulting services; also publishes Technical Traders Bulletin, a monthly newsletter containing articles of interest to technical analysts) 


\section{References and Bibliography on Managed Futures}

Allen, Gregory C. 1992. “Managed Futures: An Institutional Investor's Primer.” Paper presented at the Fourth Annual Managed Futures Symposium.

Angrist, Stanley W. 1992. "The Big Money Gives Futures a Whirl." Wall Street Journal (May 11):C1.

1991. “Virginia's Pension Plan Earmarks $\$ 100$ Million for Futures Trading." Wall Street Journal (April 26):C1.

—. 1990a. "Commodity Advisor(?) Faces an Ugly Task." Wall Street Journal (May 29):C1.

15):C1.

1990b. “Commodity Advisors Show Their Mettle." Wall Street Journal (November

—. 1990c. "Institutions Buy Futures to Cut Risks." Wall Street Joumal (December 10):C1.

- 1989. "Separating Wheat, Chaff in Commodities." Wall Street Journal (June 15):C1.

Angrist, Stanley W., and Elyse Tanouye. 1992a. "Key to Picking Managed Futures Is to Focus on Possible Drawdown." Wall Street Journal (February 21):C1.

. 1992b. "Managed Futures Can Provide a Cushion for Declines in an Investor's Portfolio." Wall Street Joumal (February 19):C1.

- 1992c. "Maze of High Fees, Costs Makes Picking Right Managed Futures Fund Critical." Wall Street Journal (February 20):C1.

_. 1991. "Professional Futures Traders Get More Money from Big Investors." Wall Street Journal (August 5):C1.

Ankrim, Ernest M., and Chris R. Hensel. 1993. "Commodities in Asset Allocation: A Real-Asset Alternative to Real Estate?" Financial Analysts Journal (May/June):20-29.

- 1992. "Exchange Traded Real Assets: Commodities in Asset Allocation." Paper presented at the Fourth Annual Managed Futures Symposium.

Association for Investment Management and Research. 1991. Performance Reporting for Investment Managers: Applying the AIMR Performance Presentation Standards. Charlottesville, Va.

Baratz, Morton S. 1989. The Investor's Guide to Futures Money Management. Columbia, Md: Futures Publishing Group.

Baratz, Morton S., and Warren Eresian. 1990. "The Role of Managed Futures Accounts in an Investment Portfolio." Paper presented at the Managed Accounts Report Conference on Futures Money Management. Reprinted in Peters, ed. (1992).

- 1986. "The Role of Managed Futures Accounts in an Investment Portfolio (I)." Paper presented at the Managed Accounts Report Mid-Year Conference on Futures Money Management. Reprinted in Peters, ed. (1992).

Barbanel, Jack, Phil Lipsky, and John Zumbrum. 1983. "Why Futures Belong in Institutional Portfolios." Futures (December):60-61, 94. 
Bennett, Phil. 1992. "The Financial Considerations of Futures Execution and Clearing." In Epstein, ed. (1992).

Billings, Al. 1990. “Rating Managed Futures Accounts.” Trader's Magazine (January):14-16.

Bodie, Zvi. 1983. "Commodity Futures as a Hedge against Inflation." The Journal of Portfolio Management (Spring):12-17. Reprinted in Peters, ed. (1992).

Bodie, Zvi, Alex Kane, and Alan J. Marcus. 1993. Investments. 2nd. ed. Homewood, Ill.: Irwin.

Bodie, Zvi, and Victor Rosansky. 1980. "Risk and Return in Commodity Futures." Financial Analysts Journal (May/June):27-39. Reprinted in Peters, ed. (1992).

Brorsen, B. Wade, and Scott H. Irwin. 1987. "Futures Funds and Price Volatility." Review of Futures Markets:119-35.

. 1985. "Examination of Commodity Fund Performance." Review of Research in Futures Markets:84-94.

Brorsen, B. Wade, and Louis P. Lukac. 1990. "Optimal Portfolios for Commodity Futures Funds." The Journal of Futures Markets:247-58.

Burke, Gibbons. 1993. "Investing in Managed Futures." Futures (July):26-27.

Chesler, Caren. 1992. "Futures Funds May Deserve a Second Look." Investors Business Daily, No. 4.

Chicago Board of Trade. 1992. "Managed Futures: An Investment Opportunity for Institutional Investors."

Chicago Mercantile Exchange. 1992. "Background Paper on Managed Futures for Institutional Investors." Paper presented at the Fourth Annual Managed Futures Symposium.

—. 1991. "Roundtable for Pension Plan Sponsors on Use of Managed Futures." Strategy paper.

1987. "Futures and Options Trading for Pension Plans: The Regulatory Environment." CME White Paper Series, No. 2.

Clarke, Roger G. 1992. Options and Futures: A Tutorial. Charlottesville: The Research Foundation of The Institute of Chartered Financial Analysts, AIMR.

Coglianese, Michael. 1992. "Ready the Bottom Line.” Futures (August):52-54.

Collins, Joseph P., and Diane V. Dygert. 1992. "Fiduciary Selection and Prohibited Transactions under ERISA." In Epstein, ed. (1992).

Cornew, Ronald. 1988. "Commodity Pool Operators and Their Pools: Expenses and Profitability.” The Journal of Futures Markets:617-37.

Crawford, William B., Jr. 1991. "Money Managers See Future in Futures." Chicago Tribune (September):1.

Doerrer, Laleen Collins. 1992. "Evaluating Commodity Trading Advisors." In Epstein, ed. (1992). 
Dunford, David M. 1990. "Futures and Options Strategies in Portfolio Management." Chapter 11 in John L. Maginn and Donald L. Tuttle. Managing Investment Portfolios. Boston, Mass.: Warren, Gorham \& Lamont.

Dunmire, Mike. 1992. "Using Alternative Investment Strategies and Managed Futures Accounts in Pension Portfolios." In Epstein, ed. (1992).

Durr, Barbara. 1992. "Managed Futures Industry Given First Break." Financial Times (May $8): 26$.

Edwards, Franklin R, and Cindy Ma. 1988. "Commodity Pool Performance: Is the Information Contained in Pool Prospectuses Useful?" The Journal of Futures Markets:589-616.

Elton, Edwin J., Martin J. Gruber, and Joel C. Rentzler. 1990. "The Performance of Publicly Offered Commodity Funds." Financial Analysts Journal (July/August):23-30. Reprinted in Peters, ed. (1992).

1 1989. "New Public Offerings, Information and Investor Rationality: The Case of Publicly Offered Commodity Funds." Journal of Business:1-15.

- 1987. "Professionally Managed, Publicly Traded Commodity Funds." Joumal of Business (April):177-99. Reprinted in Peters, ed. (1992).

Epstein, Charles B. 1992. "Introduction: Managed Futures Comes of Age." In Epstein, ed. (1992).

Epstein, Charles B., ed. 1992. Managed Futures in the Institutional Portfolio. New York: John Wiley.

Epstein, Gene. 1992. “On Track with the Industry's Thoroughbreds.” Barron's (August):39.

Fischmar, Daniel, and Carl C. Peters. 1991. "Portfolio Analysis of Stocks, Bonds, and Managed Futures Using Compromise Stochastic Dominance." The Journal of Futures Markets (June):259-70. Reprinted in Peters, ed. (1992).

Getler, Warren. 1993. "Yield Hunters Zero in on Commodities." Wall Street Journal (August 23):C1

Goldman, Sachs \& Co. 1992. "Goldman Sachs Commodity Index." Paper presented at the Fourth Annual Managed Futures Symposium.

Greising, David. 1991. "Maybe It's Time to Put a Future in Your Portfolio." Business Week (December):146-47.

Grossman, Sanford J. 1993. "A Proposal for the Reform of Disclosure Requirements for Managed Futures." Journal of Financial Engineering (March):55-58.

Hanke, Steven H., and Christopher L. Culp. 1992. "Inflation Hedging with Unleveraged Futures." In Epstein, ed. (1992).

Hart, Patrick, III, and Richard Bornhoft. 1992. "Managed Futures Being Placed in Fund Portfolios." Pension World (April):23-25.

Hart-Bornhoft Group, "Managed Futures Presentation." 
Herbst, Anthony F., and Joseph P. McCormack. 1988. "A Further Examination of the Risk/Return Characteristics of Portfolios Combining Commodity Futures Contracts with Common Stocks." Working paper, Center for the Study of Futures Markets, Columbia University. Reprinted in Peters, ed. (1992).

1986. "An Examination of the Risk/Return Characteristics of Portfolios Combining Commodity Futures Contracts with Common Stocks." Working paper, Center for the Study of Futures Markets, Columbia University. Also in Review of Research in Futures Markets (1987), pp. 416-31. Reprinted in Peters, ed. (1992).

Ibbotson Associates. 1992. "GSCI Collateralized Futures: A Hedging and Diversification Tool for Institutional Portfolios." Paper presented at the Fourth Annual Managed Futures Symposium.

Irwin, Scott H. 1994. "Further Evidence on the Usefulness of CTA Performance Information in Public Commodity Pool Prospectuses." Advances in Futures and Options Research (forthcoming).

. 1992. "The Potential Role of Managed Futures in Institutional Pension Portfolios." In Epstein, ed. (1992).

- 1990. "Justifying Managed Futures." FIA Review (July/August):10-12.

Irwin, Scott H., and B. Wade Brorsen. 1985. "Public Futures Funds." The Journal of Futures Markets (Fall):463-85. Reprinted in Peters, ed. (1992).

Irwin, Scott H., and Diego Landa. 1987. "Real Estate, Futures and Gold as Portfolio Assets." The Jourmal of Portfolio Management (Fall):29-34. Reprinted in Peters, ed. (1992).

Irwin, Scott H., Terry R. Krukemyer, and Carl R. Zulauf. 1994. "Investment Performance of Commodity Pools: 1979-1990." The Journal of Futures Markets (forthcoming).

. 1992. "Are Public Commodity Pools a Good Investment." In Peters, ed. (1992).

Irwin, Scott H., Barry A. Ward, and Carl R. Zulauf. 1992. "The Predictability of Managed Futures Returns." Paper presented at the Fourth Annual Managed Futures Symposium.

Jobman, Darrell R. 1993a. "MoMs' Nurturing Role Helps CTAs Grow." Futures (May):47-48. 1993b. "Wave of the Future(s)." Futures (April):44-45.

1992a. "Commodity Indexes: The Next Generation." Futures (October):56-58.

- 1992b. "How Managed Money Became a Major Area of the Industry." Futures (July):52-56.

—. 1992c. "Why Picking a CTA Is Not a Numbers Game." Futures (November):56, 58.

Lass, John P., and Sol Waksman. 1993. “CTA Volatility Whets Choice.” Futures (April):46, 48.

Leckey, Andrew. 1992. "Managed Futures Funds Making Inroads as Hedge for Portfolios." Chicago Tribune (May 10):6.

Lee, Cheng F., Raymond M. Leuthold, and Jean E. Cordier. 1985. "The Stock Market and the Commodity Futures Market: Diversification and Arbitrage Potential." Financial Analysts Journal (July/August):53-60. Reprinted in Peters, ed. (1992). 
Lerner, Robert L. 1989. "The Mechanics of the Commodity Futures Markets-What They Are and How They Function." Mount Lucas Management Corporation Futures Investment Series, Special Report No. 2.

Levy, Haim. 1987. "Futures, Spots, Stocks and Bonds: Multi-Asset Portfolio Analysis." The Journal of Futures Markets:383-95.

Lintner, John. 1983. "The Potential Role of Managed Commodity-Financial Futures Accounts (and/or Funds) in Portfolios of Stocks and Bonds." Paper presented at the Annual Conference of the Financial Analysts Federation (May). Reprinted in Peters, ed. (1992).

- 1965. "The Valuation of Risk Assets and the Selection of Risky Investments in Stock Portfolios and Capital Budgets." Review of Economics and Statistics (February):13-37.

Lukac, Louis, B. Wade Brorsen, and Scott H. Irwin. 1988. "Similarity of Computer Guided Technical Trading Systems.” The Journal of Futures Markets:1-14.

MacRae, Desmond. 1992. "Of Pork Bellies and Pension Funds." Global Investor (February):28. Managed Futures Association. 1992 Membership Directory. Palo Alto, Calif.

Mangieri, Gerald, and Julia Oliver. 1992. "U.S. Accounting and Taxation for Managed Futures and Options." In Epstein, ed. (1992).

Marmer, Harry. 1992. "Managed Futures: The Consultant's View." In Epstein, ed. (1992).

Mathews, Peter, and Pascal I. Magnollay. 1992. "Futures versus Stocks: A Risk Comparison." In Epstein, ed. (1992).

McLaren, John, Nancy E. Everett, and Thomas J. O'Donnell. 1992. “Managed Futures White Paper." Paper presented at the Fourth Annual Managed Futures Symposium.

Mitchell, Mark H., and David M. Kozak. 1992. “A Guide to Organizing a Commodity Pool.” In Epstein, ed. (1992).

Monmouth Capital Management. 1992. “Active Management versus the Goldman Sachs Commodity Index." Paper presented at the Fourth Annual Managed Futures Symposium.

Mossin, Jan. 1966. "Equilibrium in a Capital Asset Market." Econometrica (October):768-83.

Mount Lucas Management Corporation. 1992. "The MLM Index: A Benchmark of Managed Futures Returns." Paper presented at Fourth Annual Managed Futures Symposium.

Murphy, J. Austin. 1986. "Futures Fund Performance: A Test of the Effectiveness of Technical Analysis." The Journal of Futures Markets:175-85. Reprinted in Peters, ed. (1992).

Northcote, Thomas. 1991. "Major Events in the History of the Managed Futures Industry." MFTA Journal (Winter).

Oberuc, Richard E. 1990. "How to Diversify Portfolios of Euro-Stocks and Bonds with Hedged U.S. Managed Futures." Paper presented at the First International Conference on Futures Money Management. Reprinted in Peters, ed. (1992).

Orr, Almer H., III. 1985. "John Lintner and the Theory of Portfolio Management." Paper presented at the Sixth Annual Managed Accounts Reports Conference (February). Reprinted in Peters, ed. (1992). 
"Pension Capital May Give Boost to Commodity Fund Trading." 1992. Journal of Commerce (April):6A.

Peters, Carl C. 1992a. "A Comparative Analysis of Portfolio Diversification Criteria of Managed Futures." Paper presented at the Fourth Annual Convention of the Pennsylvania Economic Association. Reprinted in Peters, ed. (1992).

. 1992b. "Managed Futures: A Performance Perspective." In Peters, ed. (1992), pp. 3-20.

Peters, Carl C., ed. 1992. Managed Futures: Performance, Evaluation and Analysis of Commodity Funds, Pools and Accounts. Chicago: Probus Publishing.

Pike, Richard. 1991. "What Institutions Want in Managed Futures Programs." Futures (November):36j-361.

18.

Quinn, Lawrence. 1989. "Why the Rockefeller Foundation Uses the Futures Markets." Futures (January):42-43.

Ring, Trudy. 1989. "Embracing Managed Futures." Global Finance (September).

Roll, Richard. 1978. "Ambiguity When Performance Is Measured by the Security Market Line." The Journal of Finance (September):1051-69.

- 1977. "A Critique of the Asset Pricing Theory's Tests, Part I: On Past and Potential Testability of the Theory." Journal of Financial Economics (March):129-76.

Rowsell, John. 1992. "Calculating the GSCI Nearby Index." Chicago Mercantile Exchange strategy paper.

Rudderow, Timothy J. "The MLM Index." Mount Lucas Management Corporation Futures Investment Series, Special Report No. 3.

Schneeweis, Thomas. 1990. "Multi-Fund/Multi-Manager Asset Management." Paper presented at the Caisse des Depôts/Research and Development Conference on Risk Management.

Schneeweis, Thomas, Uttama Savanayana, and David McCarthy. 1992. "Multi-Manager Commodity Portfolios: A Risk/Return Analysis." In Epstein, ed. (1992).

_. 1991. "Alternative Commodity Trading Vehicles: A Performance Analysis." The Journal of Futures Markets:475-90.

Sharpe, William F. 1966. "Mutual Fund Performance." The Jourmal of Business (January), Part II:119-38.

- 1964. "Capital Asset Prices: A Theory of Market Equilibrium under Conditions of Risk." The Journal of Finance (September):425-42.

Sweica, Henry, Glenn Dubin, and George Hornig. 1992. "Experts Offer Look at Economic Value of Managed Futures." Pension. World (May):12-13.

Szala, Ginger. 1992. "What Pension Plan Pros Think of Managed Futures." Futures (April):5658. 
48.

1989a. “Multi-Asset Funds: Putting All the Pieces Together." Futures (September):46,

1989b. "What an Analysis of 690 Funds Reveals." Futures (October):64, 68.

47.

49.

1987b. "Reading a Performance Table: Not an Easy Task!" Futures (September):48-

Vannerson, Frank L., and Timothy J. Rudderow. 1991. "Effective Asset Allocation: A Comparison of Returns and Volatility." Mount Lucas Management Corporation Futures Investment Series, Special Report No. 1.

—. 1990. "The Actuarial Approach to Futures Investment." Mount Lucas Management Corporation Futures Investment Series, Special Report No. 5.

1989. "The MLM Index and Investor Profitability." Mount Lucas Management Corporation Futures Investment Series, Special Report No. 4.

Vannerson, Frank L, and Grant W. Schaumburg, Jr. 1992. "The Source of Futures Investment Returns: Implications for the Managed Futures Industry." Paper presented at the Fourth Annual Managed Futures Symposium.

Zaslow, Jeffrey, and Anne Mackay-Smith. 1984. "Public Commodity Funds Acquire Bad Image That Won't Fade Soon.” Wall Street Journal (April 24):37. 